\title{
CCR6 is required for IL-23-induced psoriasis-like inflammation in mice
}

\author{
Michael N. Hedrick, ${ }^{1}$ Anke S. Lonsdorf, ${ }^{2,3}$ Aiko-Konno Shirakawa, ${ }^{1}$ \\ Chyi-Chia Richard Lee,, ${ }^{4}$ Fang Liao, ${ }^{1}$ Satya P. Singh, ${ }^{1}$ Hongwei H. Zhang, ${ }^{1}$ \\ Alexander Grinberg, ${ }^{5}$ Paul E. Love, ${ }^{5}$ Sam T. Hwang, ${ }^{2}$ and Joshua M. Farber ${ }^{1}$
}

\begin{abstract}
${ }^{1}$ Inflammation Biology Section, Laboratory of Molecular Immunology, National Institute of Allergy and Infectious Diseases (NIAID), and
2Dermatology Branch, Center for Cancer Research, National Cancer Institute (NCI), NIH, Bethesda, Maryland, USA.

${ }^{3}$ Department of Dermatology, University Hospital Heidelberg, Heidelberg, Germany. ${ }^{4}$ Laboratory of Pathology, Center for Cancer Research, NCl, and

${ }^{5}$ Laboratory of Mammalian Genes and Development, National Institute of Child Health and Human Development (NICHD), NIH, Bethesda, Maryland, USA.
\end{abstract}

\begin{abstract}
Psoriasis is a common immune-mediated chronic inflammatory skin disorder, but the mechanisms of pathogenesis are still poorly understood. IL-23 is expressed in psoriatic skin, and IL-23 injection produces IL-22-dependent psoriasiform changes in mouse skin. Th17 cells produce IL-22 and display CCR6, the CCL20 receptor; $\mathrm{CCR6}^{+} \mathrm{T}$ cells and CCL20 are abundant in psoriatic skin. We investigated a possible role for CCR6 in recruiting Th17 cells and producing psoriasiform pathology by injecting IL-23 into the skin of WT and $\mathrm{Crr6}^{-/-}$mice. Unlike for WT mice, IL-23-injected ears of $\mathrm{Ccr6}^{-/-}$mice showed neither substantial epidermal/dermal changes nor increased Il22 mRNA expression. However, injection of IL-22 yielded equivalent psoriasiform changes in WT and $\mathrm{Crr6}^{-/-}$mice. Surprisingly, IL-23-injected ears of WT and $\mathrm{Ccr}^{-/-}$mice contained similar numbers of Th cells able to make IL-17A and/or IL-22. Furthermore, in ears of $\mathrm{Rag}^{-/-}$mice, IL-23 initially induced skin changes and levels of Il22 $\mathrm{mRNA}$ that were indistinguishable from WT mice, revealing at least one non-T cell source for IL-22. We conclude that CCR6 is essential in a model of IL-23-induced, IL-22-mediated dermatitis, which develops in sequential T cell-independent and $T$ cell-dependent phases. These findings reveal an expanded role for CCR6 in IL-23-related responses and identify CCR6 as a potential therapeutic target in psoriasis.
\end{abstract}

\section{Introduction}

Psoriasis is one of the most common immune-mediated chronic inflammatory skin disorders in adults, affecting $1 \%-2 \%$ of white individuals, with a considerable impact on quality of life (1). Defining histological features of psoriatic skin lesions include epidermal hyperplasia (acanthosis), caused by aberrant terminal differentiation and hyperproliferation of epidermal keratinocytes, as well as marked infiltration of mononuclear leukocytes into the dermis (2). While an underlying genetic component to the disease has been acknowledged for many years (1-3), important aspects of the complex autoimmune inflammatory mechanisms involved in the pathogenesis of psoriasis are still poorly understood.

Experimental data from various animal models of psoriasis, as well as the clinical effectiveness of newer systemic therapeutics targeting activated $\mathrm{T}$ lymphocytes, strongly implicate $\mathrm{T}$ cells in the pathogenesis of this disease (2). Psoriasis has traditionally been classified as a Th1-mediated disease. One reason is the abundance of IFN- $\gamma$-producing, Th1-polarized T cells within psoriatic skin. A second reason is that TNF- $\alpha$, another type 1 cytokine produced by several skin immune cells, is highly upregulated in psoriatic lesions $(3,4)$. TNF- $\alpha$ undoubtedly plays a pathogenic role in the development of psoriasis, as TNF- $\alpha$ inhibitors, such as etanercept and infliximab, are highly effective therapies (5-8).

Authorship note: Michael N. Hedrick and Anke S. Lonsdorf contributed equally to this work.

Conflict of interest: J.M. Farber has stock holdings in General Electric, Medco Health Solutions, and CardioMag Imaging. A. Grinberg has stock holdings in ISIS Pharmaceuticals, Alnylam Pharmaceuticals, and Rigel Pharmaceuticals.

Nonstandard abbreviations used: PI, propidium iodide.

Citation for this article: J. Clin. Invest. 119:2317-2329 (2009). doi:10.1172/JCI37378.
In spite of the data implicating Th1 cells in psoriasis, recent research has drawn attention to the significance of Th17 cells, a newly identified Th cell subset, in the pathogenesis of psoriasis and other autoimmune inflammatory disorders (9-13). Th17 cells and their downstream effector molecules, which include IL-17A, IL-17F, TNF- $\alpha$, and IL-22 $(14,15)$, have been found at increased levels in human psoriatic skin (16-20). In support of a role for Th17 cells in psoriasis, Zaba et al. demonstrated that reduced Th17 responses in patients treated with etanercept correlated with clinical improvement (21). Moreover, psoriatic skin lesions contain high levels of IL-23 compared with nonlesional and normal skin $(20,22,23)$. IL-23 is a heterodimeric cytokine that shares its p40 subunit with IL-12 (24), and that functions as a key differentiation and growth factor for Th17 cells (11, 25-28). Genome-wide screening has revealed associations between the development of psoriasis and polymorphisms in the genes not only for the p40 subunit, but also for the p19 subunit and the IL-23-specific chain of the IL-23 receptor (29-32); moreover, ustekinumab, an antibody that blocks the activity of $\mathrm{p} 40$, has produced dramatic clinical responses in patients with chronic plaque psoriasis (33-35).

In support of a role for the IL-23/Th17 axis in psoriasis, it was recently reported that injection of IL-23 into the skin of WT mice induces some psoriasiform changes, such as acanthosis, hyperparakeratosis, and dermal inflammatory infiltrates, yet fails to induce other aspects of the human disease, such as epidermis-infiltrating $\mathrm{CD}^{+} \mathrm{T}$ cells $(36,37)$. IL-22, a member of the IL-10 family of cytokines and a product of activated Th17 cells, is a critical mediator of the psoriasiform changes, since IL-22 deficiency abrogates much of the acanthosis and dermal inflammation induced by IL-23 (38). In addition, in a model using adoptive transfer of $\mathrm{CD}^{+}{ }^{+} \mathrm{CD} 45 \mathrm{RB}^{\mathrm{hi}} \mathrm{CD} 25^{-}$cells into scid mice, neutralizing IL-22 pre- 
A
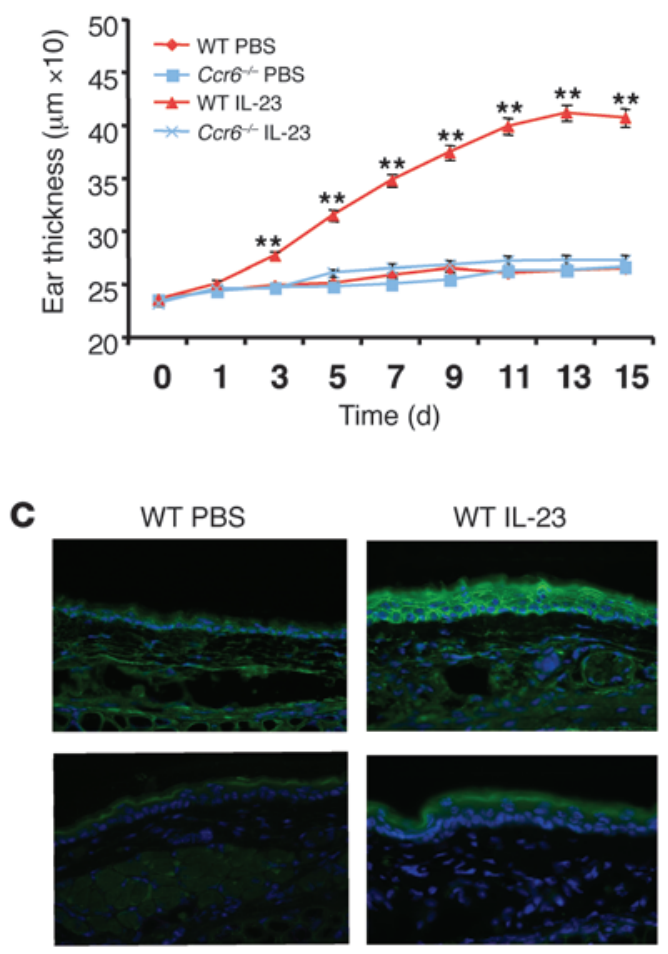

B

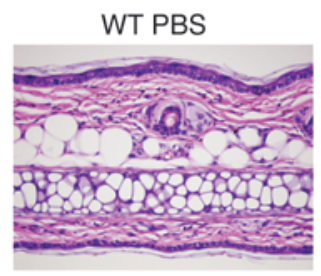

WT IL-23
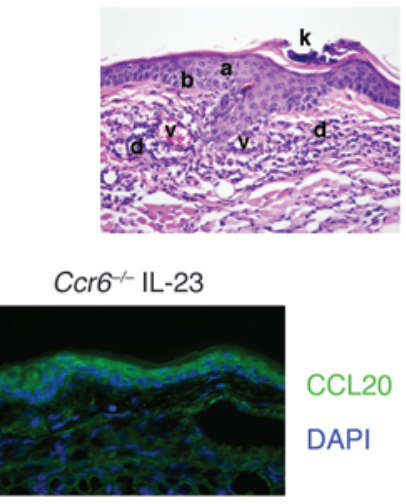

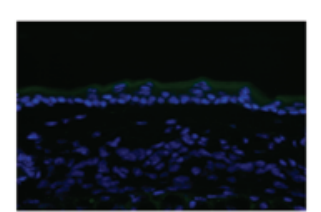

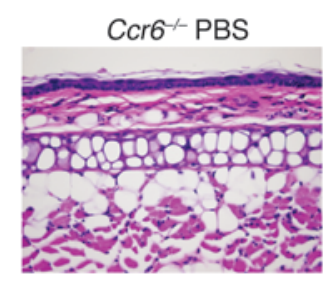

$\mathrm{CcrG}^{-1} \mathrm{IL}-23$

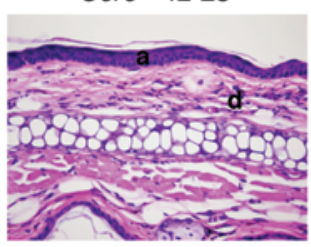

D

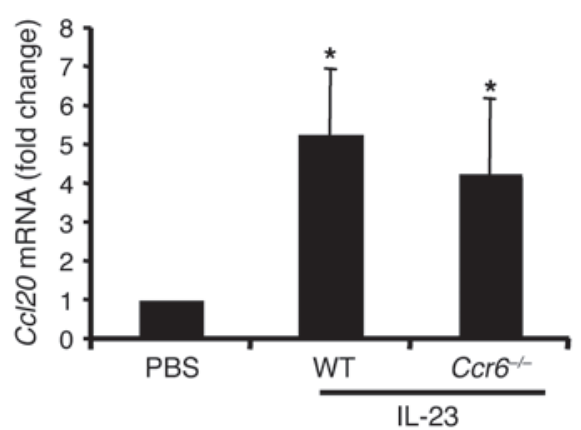

Figure 1

$\mathrm{Ccr6}^{-/-}$mice are resistant to IL-23-induced acanthosis and dermal inflammation. Ears of WT and Ccr6-/- mice were injected intradermally every other day for 16 days with $20 \mu \mathrm{l}$ PBS, either alone or containing $500 \mathrm{ng}$ IL-23. (A) Ear thickness was measured on days between injections. Data are from 5 experiments in at least 30 mice/group. ${ }^{\star *} P<0.01$ versus all other groups. (B) H\&E-stained sections of PBS- or IL-23-injected ears from WT and $\mathrm{Ccr6}^{-/-}$mice at day 15. k, hyperparakeratosis with intracorneal neutrophilic pustule; $\mathrm{a}$, acanthosis; $\mathrm{b}$, increased proliferative activity of basal layer epidermal keratinocytes; $d$, dermal mononuclear cell infiltrate; $v$, telangiectasia of dermal blood vessels. Sections are representative of 2 experiments. (C) Frozen sections of ears from WT PBS-injected or WT and Ccr6-/- IL-23-injected mice on day 15 stained with rat anti-mouse CCL20 or isotype-matched control antibody followed by Alexa Fluor 488-conjugated goat anti-rat lgG (green). Nuclei were counterstained with DAPI. Staining is representative of 2 experiments. (D) mRNA for Cc/20 and Gapdh were measured by real-time RT-PCR at day 15 from ears of WT PBS-injected or WT and $\mathrm{Ccr6}^{-/}$IL-23-injected mice. Fold changes normalized for Gapdh mRNA are shown versus the PBS-injected ears. Data are from 3 experiments in at least 5 mice/group. ${ }^{*} P<0.05$ versus PBS control. Original magnification, $\times 400$.

vented the psoriasis-like skin disease (39). In human studies, IL-22 has been found to produce psoriasiform changes in reconstituted epidermis (40), increased expression of IL-22 has been found in psoriatic skin, and serum levels of IL-22 are elevated in patients with chronic plaque psoriasis - correlating positively with severity of disease and negatively with response to therapy (41-43). Until now, infiltrating Th17 cells have been suggested to be the source of the IL-22 in skin $(38,43)$. These recent data strongly implicate Th17 cells along with their upstream cytokine, IL-23, and their downstream effector cytokine, IL-22, in the pathogenesis of psoriasis.

Such advances notwithstanding, the factors important for migration, maintenance, and function of Th17 cells at the site of cutaneous inflammation are not well understood. Chemokines and their receptors are essential components in leukocyte migration (44-46), and studies of the differential expression of chemokine receptors have been helpful in characterizing subsets of human $T$ cells with distinct migratory and effector profiles $(47,48)$. For example, the chemokine receptor CCR6 is found on virtually all human CD4 ${ }^{+}$ $\mathrm{T}$ cells capable of producing IL-17A, IL-17F, and IL-22 (refs. 13, 49-52, and S.P. Singh and J.M. Farber, unpublished observations), and CCL20, the sole chemokine ligand for CCR6, is produced by Th17/CCR $6^{+}$cells (refs. 13, 23, and S.P. Singh and J.M. Farber, unpublished observations). These relationships make observations on CCR6 and CCL20 in psoriasis of particular interest. CCL20 is highly expressed in the epithelium of psoriatic skin and is inducible by IL-1 $\beta$, IFN- $\gamma$, and IL-17A in multiple skin cell types (53). CCR6 is found on a significant fraction of $\mathrm{CLA}^{+}$(skin homing) $\mathrm{CD}^{+} \mathrm{T}$ cells $(53,54)$ and on approximately $75 \%$ of $\mathrm{CD}^{+} \mathrm{T}$ cells resident in normal skin (55) as well as on $\mathrm{T}$ cells in psoriatic epidermis (56).

CCR6 is a chemokine receptor that was discovered initially by its expression on subsets of dendritic cells and T cells (57). CCR6 has been reported to be of particular importance at mucosal sites. Compared with WT mice, $\mathrm{Crr}^{-1-}$ mice have smaller Peyer patches (58), fewer associated $\mathrm{M}$ cells (58), and defective formation of isolated lymphoid follicles (59). Abnormalities in intestinal immune responses have been reported for $\mathrm{Ccr}^{-/-}$mice in models of inflammatory bowel disease (60) and during infection with rotavirus (61) and Salmonella typhimurium (62). In the skin, $\mathrm{Crr}^{-/-}$mice have been reported to develop either more (58) or less (63) severe contact hypersensitivity as well as diminished delayed-type hypersensitiv- 

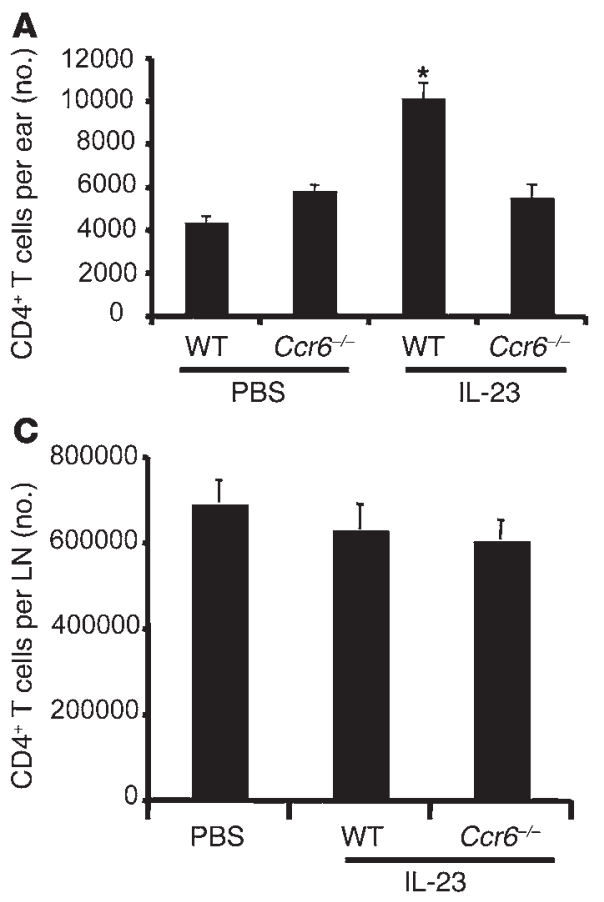
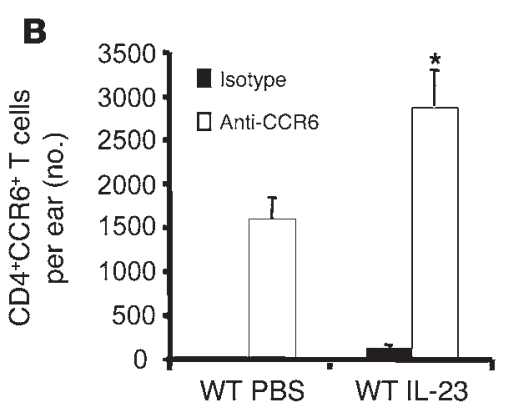

D

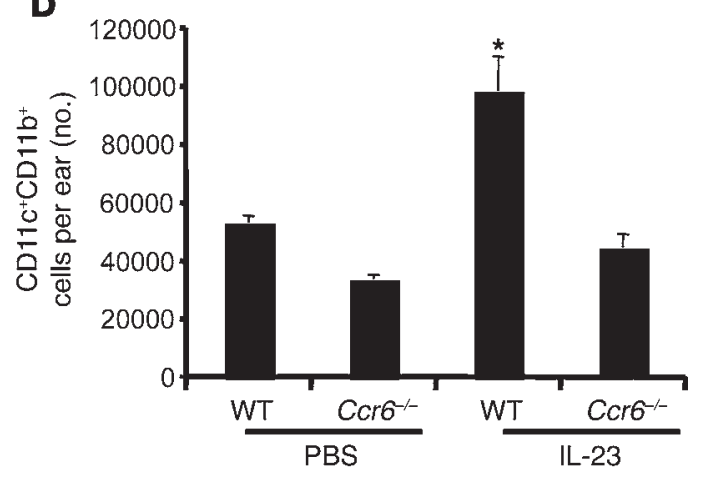

Figure 2

IL-23 injections increase the number of $\mathrm{CD}^{+}{ }^{+} \mathrm{T}$ cells and dendritic cells in ears of WT mice, but not $\mathrm{Ccr6}^{-/-}$mice. Ears were injected as in Figure 1. On day 15 , cells were stained and analyzed on a flow cytometer using counting beads. (A) Number of CD4+ $T$ cells per PBS- or IL-23-injected ear of WT and $\mathrm{Ccr6}^{-/-}$mice. (B) Number of $\mathrm{CD}^{+}{ }^{+} \mathrm{CCR} 6{ }^{+} \mathrm{T}$ cells per ear of WT mice. Cells were stained with anti-mouse CCR6 or an isotype control. (C) Number of CD4+ $\mathrm{T}$ cells per cervical lymph node of PBS-injected WT or IL-23injected WT and $\mathrm{Ccr6}^{-/-}$mice. (D) $\mathrm{CD} 11 \mathrm{c}^{+} \mathrm{CD} 11 \mathrm{~b}^{+}$(dendritic) cells per PBS- or IL-23-injected ear of WT and $\mathrm{CCr6}^{-/-}$mice. Data are from 3 mice/group in 1 representative experiment of 8 (A, B, and $\mathbf{D}$ ) or $5(\mathbf{C})$. ${ }^{*} P<0.05$ versus all other groups. ity (58) and graft-versus-host-mediated injury (64). In this study, we assessed the role of CCR6 in psoriasiform changes after injection of IL-23 into mouse skin and found that the IL-23-induced pathology was CCR6 dependent. Furthermore, contrary to our expectations, our findings suggest that the requirement for CCR6 is not through a direct effect on T cells, but rather by establishing an inflammatory response that is initially $\mathrm{T}$ cell independent and that includes a non- $\mathrm{T}$ cell source of IL-22.

\section{Results}

CCR6 is required for IL-23-induced psoriasiform inflammation. Consistent with previous reports (36-38), intradermal injection of ears of WT mice with IL-23 induced marked ear swelling. Ear thickness increased by more than $100 \mu \mathrm{m}$ compared with PBS-injected controls after injecting IL-23 every other day over the 16-day experiment (Figure 1A). To test the role of CCR6 in this response, we used $\mathrm{Crr}^{-/-}$mice that we generated by gene targeting (Supplemental Figure 1; supplemental material available online with this article; doi:10.1172/JCI37378DS1). As shown in Figure 1A, the ears of the $\mathrm{Crr6}^{-/-}$mice did not swell after injections of IL-23. H\&E staining of sections from injected WT ears on day 15 revealed the epidermal changes described previously, namely acanthosis (thickening of the spinous layer), hyperparakeratosis (retention of nuclei within the stratum corneum), dermal inflammatory infiltrates, and telangiectasis (dilated capillaries and venules; Figure 1B). Occasional intracorneal neutrophils were found, but were not conspicuous (see below). Conversely, IL-23 injection had a minimal effect on $\mathrm{Crr}^{-/-}$ears, comparable to that on the PBS-injected controls.

If the role of CCR6 in this model is a direct one at the site of injection, then CCL20, the sole chemokine ligand for CCR6, should be induced in the injected ears. CCL20 protein and Ccl20 mRNA were indeed detected by immunohistochemistry (Figure 1C) and RT-PCR (Figure 1D), respectively. Prominent upregulation of CCL20 was seen in acanthotic mouse epidermis, as previously described for psoriatic skin (53). CCL20 protein and Ccl20 mRNA were induced similarly in WT and $\mathrm{Crr}^{-/-}$ears, which suggests that CCR6 itself is not required for their upregulation.

$\mathrm{Ccr6}^{-1-}$ mice do not accumulate $\mathrm{CD} 4^{+} \mathrm{T}$ cells or $\mathrm{CD} 11 c^{+} \mathrm{CD} 11 b^{+}$dendritic cells in response to intradermal IL-23 injection. To determine the composition of the IL-23-induced inflammatory infiltrate and quantify differences between WT and $\mathrm{Crr}^{-/-}$ear cells, we prepared single-cell suspensions from treated skin and analyzed them by flow cytometry. Injections with IL-23 led to an approximately 2 -fold increase in total $\mathrm{CD}^{+} \mathrm{T}$ cells compared with control PBS injection in WT ears, but no such increase was observed in $\mathrm{Crr}^{-/}$ears (Figure 2A). Analysis of $\mathrm{CCR} 6^{+} \mathrm{CD} 4^{+} \mathrm{T}$ cells in WT mice showed that this subset also increased in the IL-23-injected ears (Figure 2B). We found no significant increases in NK1.1 $1^{+}$cells, $\gamma \delta$ T cells, macrophages, or neutrophils in the IL-23-injected ears and no difference in the number of these cells between WT and $\mathrm{Cr}^{-/-}$ears (data not shown). Trivial numbers of $\mathrm{CD}^{+} \mathrm{T}$ cells were present in the ears, again not increasing after IL-23 injections and not different between WT and $\mathrm{Crr6}^{-/-}$mice (data not shown). We also found no differences in the number of $\mathrm{CD}^{+} \mathrm{T}$ cells in the noninjected ears between WT and $\mathrm{Crr6}^{-/-}$mice, with numbers similar to those injected with PBS (data not shown). Differences in cell numbers in the IL-23-injected ears of WT and $\mathrm{Crr}^{-/-}$mice appeared to be limited to the site of injection, because the number of $\mathrm{CD}^{+}{ }^{+} \mathrm{T}$ cells was similar in the draining, cervical lymph nodes and was not affected by IL-23 injections (Figure 2C). For the $\mathrm{CD} 11 \mathrm{c}^{+} \mathrm{CD} 11 \mathrm{~b}^{+}$subset of dendritic cells, results were similar to that seen for the $\mathrm{CD}^{+} \mathrm{T}$ cells: a 2 -fold increase in WT ears, but not $\mathrm{Crr}^{-/-}$ears, after IL-23 injections (Figure 2D). In contrast, no difference between $\mathrm{Ccr}^{-/-}$and WT mice was detected with regard to the number of $\mathrm{CD} 11 \mathrm{c}^{+} \mathrm{CD} 11 \mathrm{~b}^{+}$cells in noninjected ears or in the cervical lymph nodes of IL-23-injected or PBS-injected animals (data not shown).

Ccr6 ${ }^{-1-}$ mice produce less IL-22 after IL-23 injections. IL-22 has been previously reported to be induced in ears after IL-23 injection and to be critical for the IL-23-induced changes in the skin (38). Consistent with this report, we found elevated levels of Il22 mRNA in 

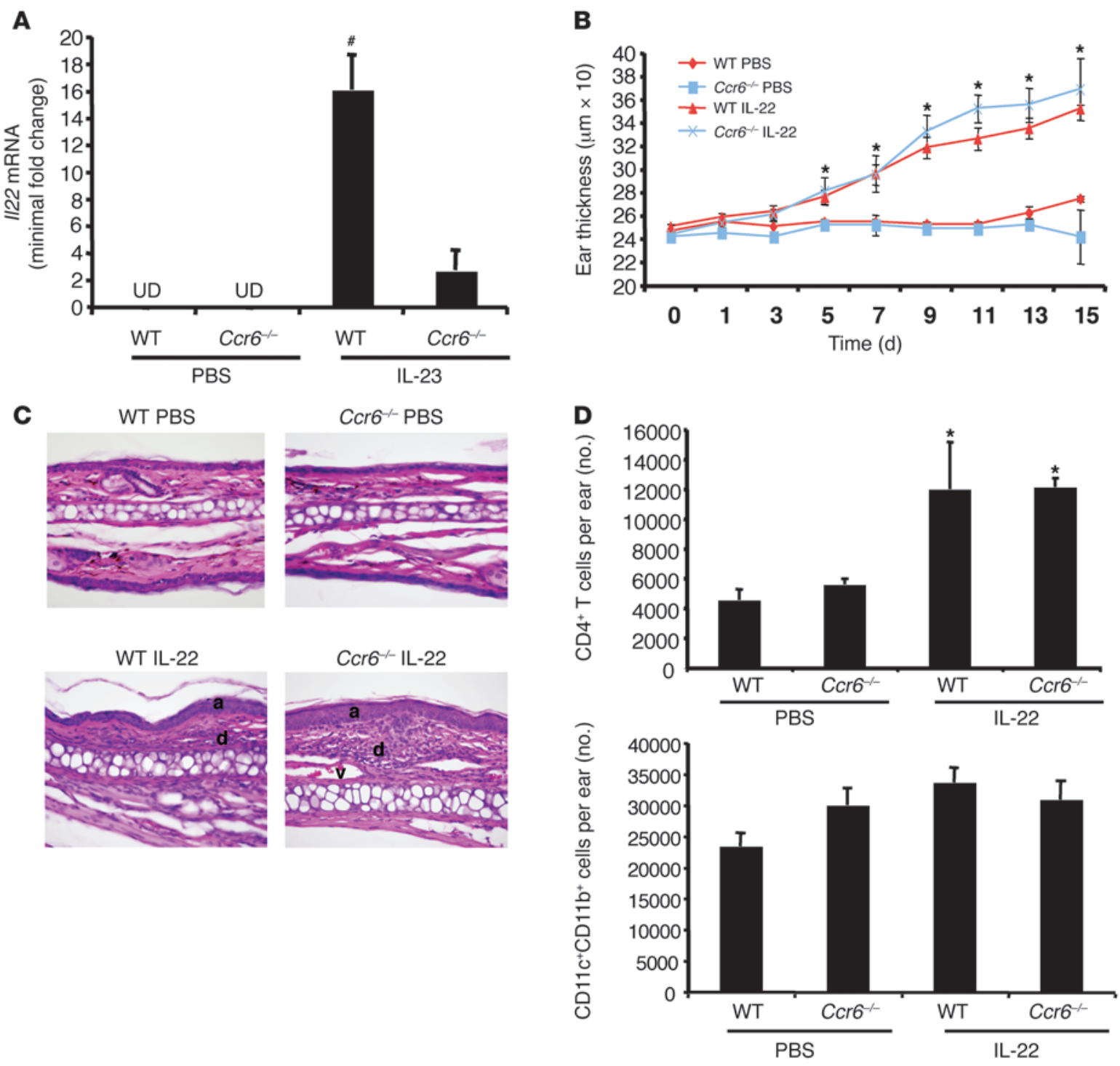

Figure 3

IL-22 production deficiency is the critical factor in protection against psoriasis-like changes in $\mathrm{Ccr}^{-/-}$mice. (A) Ears were injected as in Figure 1, and mRNAs for II22 and Gapdh were measured by real-time RT-PCR at day 15. mRNA for II22 was undetectable (UD) in PBS-injected ears; $\mathrm{Ct}$ for these samples was set at 37, the limit of detection determined experimentally. Minimal fold changes were calculated for I/22 mRNA normalized for Gapdh mRNA versus the PBS-injected sample with the greatest $\Delta$ Ct. Data are from 5 experiments in 12 IL-23-injected and 4 PBSinjected mice/group. ${ }^{P}<0.05$ versus all other groups. (B-D) Ears were injected as in Figure 1, except that $500 \mathrm{ng} I \mathrm{~L}-22 \mathrm{was}$ used in place of IL-23. (B) Ear thickness, measured as in Figure 1A. Data are from 2 experiments in 16 mice/group. ${ }^{*} P<0.05$, IL-22-injected versus PBS control. (C) H\&E-stained sections of PBS- or IL-22-injected ears of WT and Ccr6 ${ }^{-1-}$ mice on day 15. Sections are representative of 2 experiments. (D) Total numbers of CD4 ${ }^{+} \mathrm{T}$ cells and CD11 $\mathrm{c}^{+} \mathrm{CD} 11 \mathrm{~b}^{+}$(dendritic) cells from PBS- or IL-22-injected ears from WT and Ccr6 ${ }^{-1-}$ mice, measured as in Figure 2. Data are from 5 mice/group in 1 representative experiment of 2 . ${ }^{*} P<0.05$ versus PBS control. Other pairwise comparisons did not yield significant differences. Original magnification, $\times 400$.

the IL-23-injected WT ears. However, induction of Il22 mRNA in $\mathrm{Ccr6}^{-1-}$ ears was much reduced (Figure 3A). If lower levels of IL-22 induction in the ears were responsible for the overall failure of the $\mathrm{Crr6}^{-/-}$mice to respond to IL-23, then injecting IL-22 into the ears would be expected to produce similar changes in $\mathrm{Crr6}^{-/-}$and WT mice. WT and $\mathrm{Crr}^{-/-}$ears swelled in parallel in response to IL-22 (Figure 3B), although IL-22 produced somewhat less swelling in the WT mice than did IL-23 (compare with Figure 1A). H\&E staining of sections from the IL-22-injected ears showed acanthosis, dermal inflammation, and dilatation of dermal vasculature that were comparable in the WT and $\mathrm{Crr}^{-/-}$mice (Figure 3C), although changes in the WT mice were again more modest than those seen after IL-23 injections (compare with Figure 1B). As done for the ears in the IL-23 experiments, we prepared single-cell suspensions from PBSand IL-22-injected ears and analyzed them by flow cytometry. IL-22 injection induced an approximately 2 -fold increase in the number of CD4 ${ }^{+} \mathrm{T}$ cells in both WT and $\mathrm{Ccr6}^{-/-}$ears (Figure 3D), similar to the increases seen after IL-23 injection in the WT mice (compare 


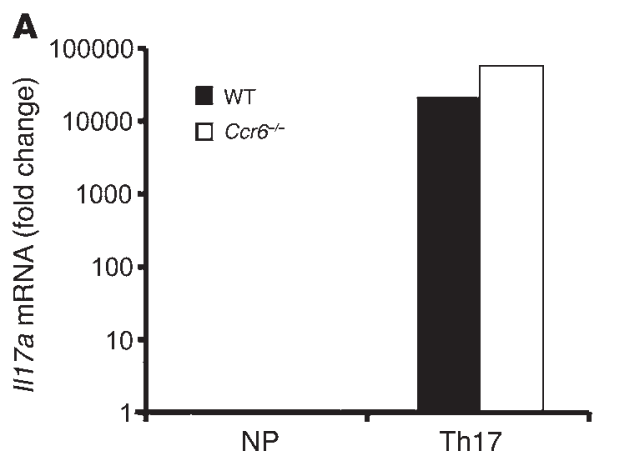

B

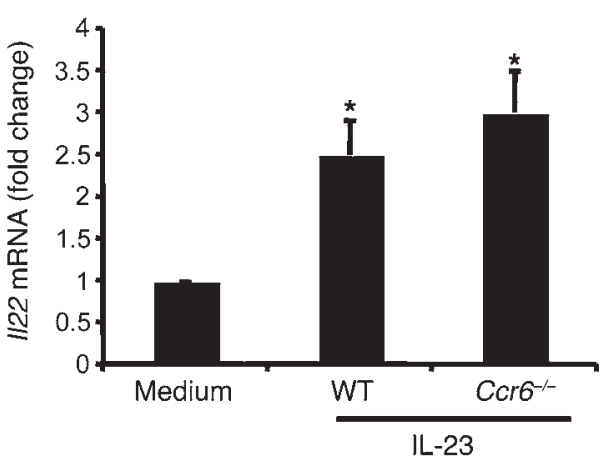

Figure 4

CD4 ${ }^{+} \mathrm{T}$ cells from $\mathrm{Ccr6}^{-/-}$mice are able to differentiate into Th17/IL-22-producing cells. (A) Naive $\mathrm{CD}^{+} \mathrm{T}$ cells $\left(\mathrm{CD}_{2} \mathrm{~L}^{+} \mathrm{CD} 44^{\mathrm{lo}} \mathrm{CD} 25^{-}\right)$were purified from WT or $\mathrm{Ccr6}^{-/-}$mice and activated and cultured under nonpolarizing (NP) or Th17-polarizing conditions. After 7 days, cells were treated with PMA and ionomycin, and mRNAs for $/ 117 a, I / 22$, and Gapdh were measured by real-time RT-PCR. Fold changes were calculated for I/17a and I/22 mRNAs normalized for Gapdh mRNA versus the nonpolarized sample with the greatest $\Delta \mathrm{Ct}$ within each plot. Values denote cells from WT or Ccr6 ${ }^{-1}$ mice from a single representative experiment of 4. (B) Splenocytes were cultured in medium alone or with $100 \mathrm{ng} / \mathrm{ml} \mathrm{IL-23} \mathrm{for} 12$ hours, and mRNAs for II22 and Gapdh were measured by real-time RT-PCR. Fold changes were calculated for values of II22 mRNA normalized for Gapdh mRNA versus WT cells in medium alone. Data are from 3 samples from WT or Ccr6 $6^{-1-}$ mice in 1 representative experiment of 2. ${ }^{*} P<0.05$ versus medium. Values for IL-23-treated splenocytes from WT and $\mathrm{CCr6}^{-/-}$mice were not significantly different.

with Figure 2A). However, unlike the IL-23 injections, IL-22 injection did not induce the accumulation of $\mathrm{CD} 11 \mathrm{c}^{+} \mathrm{CD} 11 \mathrm{~b}^{+}$dendritic cells (Figure 3D). Moreover, we found no significant increases in $\mathrm{CD}^{+} \mathrm{T}$ cells, NK1.1 $1^{+}$cells, $\gamma \delta \mathrm{T}$ cells, macrophages, or neutrophils in IL-22-injected ears (data not shown).

We presumed that the lack of IL-22 in the ears of $\mathrm{Crr}^{-/-}$mice was due to a failure of IL-22-producing cells to traffic to the site. However, to rule out an essential defect in the ability of cells from $\mathrm{Ccr}^{-/-}$ mice to make IL-22, we performed experiments using splenocytes and $\mathrm{CD} 4^{+} \mathrm{T}$ cells ex vivo. Naive $\mathrm{CD} 4^{+} \mathrm{T}$ cells purified from WT and $\mathrm{Crr6}^{-/-}$mice were cultured for 7 days under either nonpolarizing or Th17-polarizing conditions, and Il17a and Il22 mRNA levels were measured after restimulation. Il17 $a$ and $I l 22$ mRNAs were highly induced in cells cultured under Th17-polarizing conditions, and these levels did not differ between cells from WT and $\mathrm{Crr6}^{-/-}$mice (Figure 4A). Similarly, IL-23 induced Il22 mRNA to equal levels in unfractionated splenocytes from WT and $\mathrm{Ccr6}^{-/-}$mice (Figure 4B). Most likely, then, the low levels of IL-22 in the IL-23-injected $\mathrm{Crr}^{-/-}$ears were not caused by an inherent inability of $\mathrm{Ccr}^{-/-}$cells to produce IL-22, but rather by differences between $\mathrm{Ccr6}^{-/-}$and WT mice in an IL-22-producing population of cells resident in the ear under homeostatic conditions and/or recruited after injection of IL-23.

Ears from WT and $\mathrm{Ccr6}^{-/-}$mice contain similar numbers of Th17 cells after $I L-23$ injection. Among the lineages of $\mathrm{CD}^{+}$ effector/memory cells, IL-22 is produced by Th17 cells, and these cells have been suggested as the source of IL-22 in psoriatic skin (43) and in the IL-23-injection model of psoriatic inflammation (38). Consistent with previous data on mouse and human cells (13, 49-52), after IL-23 injections, a high percentage of Th17 cells in WT ears expressed CCR6 (Figure 5A). Surprisingly, although we found significant induction of Il17 $a$ and Il17f mRNA in IL-23-injected ears, there were no differences in levels between $\mathrm{Ccr6}^{-/-}$and WT mice (Figure 5B). Intracellular staining of ear $\mathrm{CD}^{+} \mathrm{T}$ cells for IL-17A and IL-22 after activation ex vivo showed that, in fact, $\mathrm{Crr}^{-/-}$ ears contained higher percentages of IL-17A-producing cells than did WT ears and little change in the frequency of these cells after IL-23 injections (Figure 5C). While $\mathrm{Ccr6}^{-/-}$mice had higher absolute numbers of Th17 cells in PBS-injected control ears, there were similar numbers of Th17 cells per ear in the WT and $\mathrm{Ccr6}^{-/-}$mice after IL-23 injections (Figure 5D), the result of failure to recruit additional Th17 cells - as well as non-Th17 T cells - in $\mathrm{Ccr6}^{-/-}$ears coupled with the increase in Th17 cells in WT ears. It bears noting that a significant percentage of $\mathrm{T}$ cells able to produce IL-17A in mouse skin are $\gamma \delta \mathrm{T}$ cells, although these cells are not able to produce IL-22 (65). As noted above, we saw no difference in the number of $\gamma \delta$ T cells after IL-23 injection or between $\mathrm{Ccr}^{-/-}$and WT mice. We did detect $\mathrm{CD}^{+} \mathrm{CD} 4-\mathrm{IL}-17^{+}$cells from the ears after activation ex vivo, but again, the numbers did not differ between PBS- and IL-23-injected or between $\mathrm{Ccr}^{-/-}$and WT mice (data not shown).

We detected small numbers of IL-22-producing $\mathrm{CD}^{+} \mathrm{T}$ cells after activation ex vivo, but only in IL-23-injected ears (Figure 5C). IL-22-producing cells were highly enriched within the IL-17A-producing subset. Cells were also identified within the IL-22+IL-17A- quadrant, although their tendency to sit just to the left of the IL-17A gate suggests they might be IL-17A ${ }^{\text {lo. }}$. The number of cells capable of producing IL-22 was similar in WT and $\mathrm{Cr}^{-/-}$ears (Figure 5D). The findings from intracellular staining for IL-22 were supported by measuring the IL-22 produced by ear $\mathrm{T}$ cells after stimulating with anti-CD3 ex vivo. We detected secretion of IL-22 only by cells from IL-23-injected ears, and similar amounts of IL-22 were produced by cells from WT and $\mathrm{Ccr}^{-/-}$mice (Figure 5E). In addition to analyzing ears for Il22, Il17a, and Il17f, we also performed RT-PCR for Tnfa and Ifng mRNA. Ifng mRNA was not detectable, and Tnfa mRNA 
A

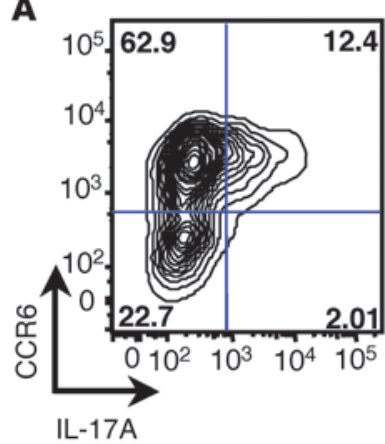

C

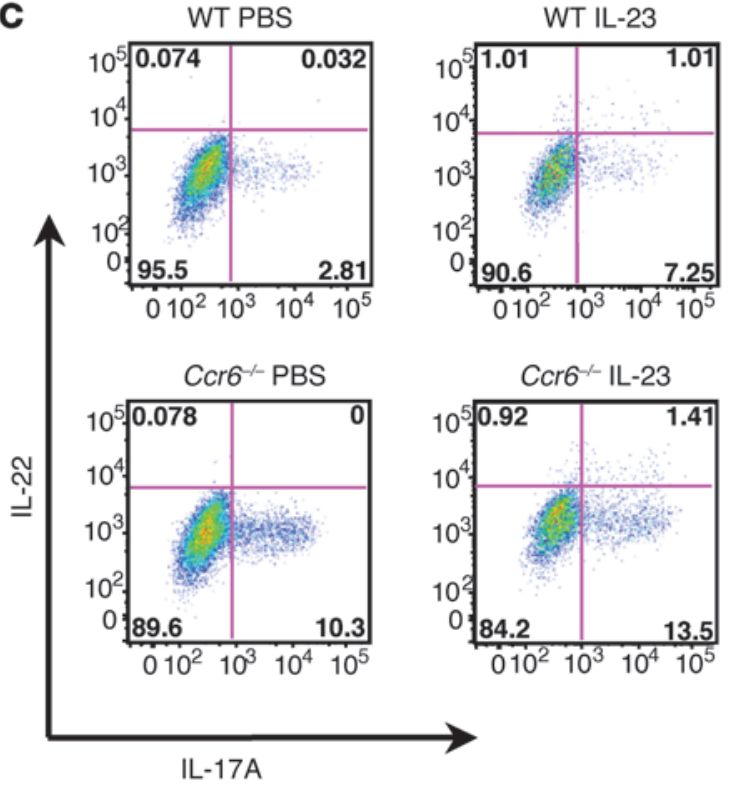

E

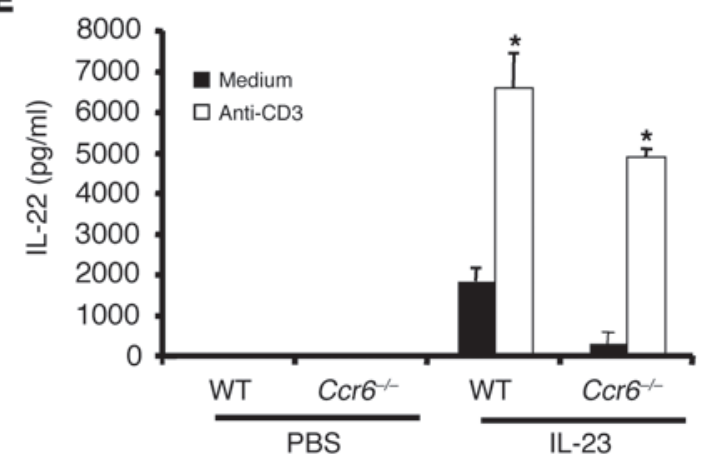

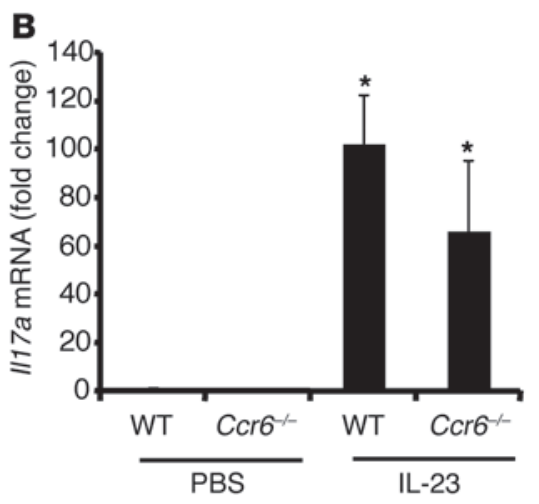

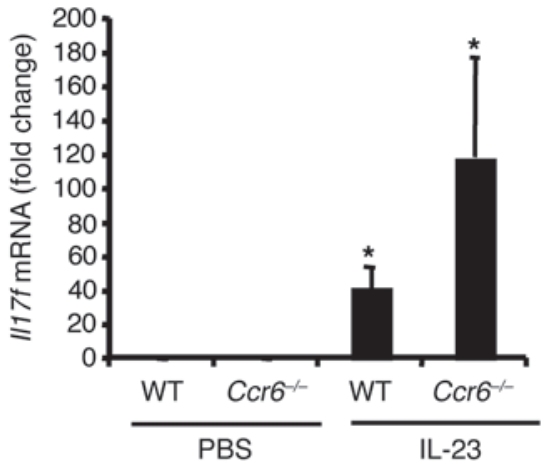

D
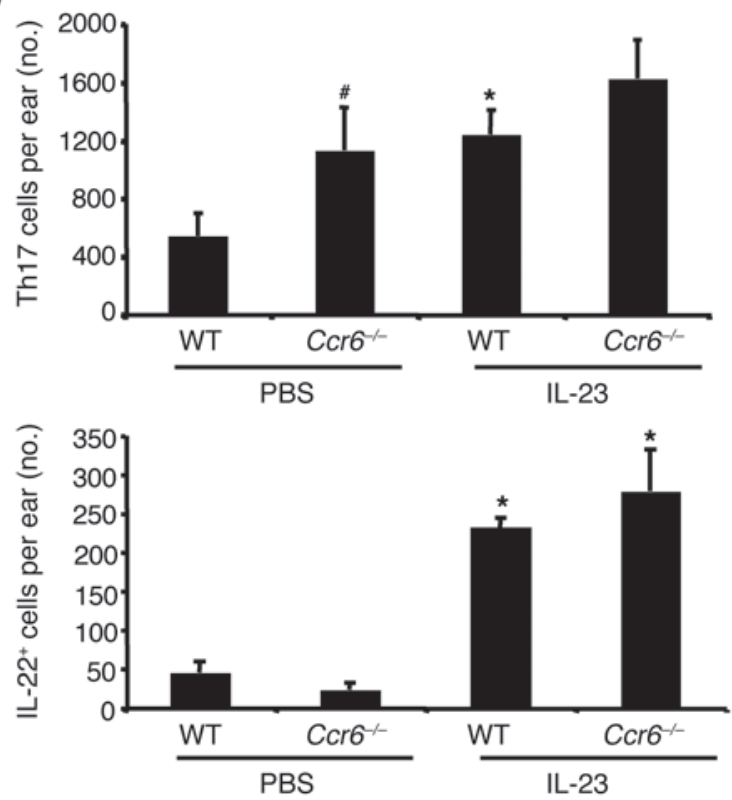

Figure 5

IL-23-injected ears of WT and Ccr6-/- mice have similar IL17a and II17f mRNA, Th17 cells, and IL-22-producing cells at day 15. Ears were injected as in Figure 1 and harvested on day 15. (A) Cells from IL-23-injected WT ears were activated with PMA and ionomycin, stained, and analyzed. Shown are $\mathrm{CD}^{+} \mathrm{CD} 4^{+}$cells only, from 1 mouse in 1 representative experiment of 6 . (B) mRNAs were measured by real-time RT-PCR. Data are Gapdh-normalized fold changes versus the PBS-injected sample with the greatest $\Delta$ Ct, from 5 experiments in 12 (IL-23) and 4 (PBS) mice/group. (C) Cells were activated with PMA and ionomycin, stained, and analyzed. Shown are CD3 ${ }^{+} \mathrm{CD} 4^{+}$cells only, from a sample pooled from 3 ears in 1 representative experiment of 3 . (D) Total IL-17A- or IL-22-expressing CD3 ${ }^{+}$CD4 ${ }^{+}$T cells analyzed as in C. Data are from at least 14 mice/group in 8 experiments (IL-17A) or from 3 pooled samples of 3 ears/group in 1 representative experiment of 3 (IL-22). (E) Cells were cultured in medium alone or with $10 \mu \mathrm{g} / \mathrm{ml}$ soluble anti-CD3 for 12 hours, and IL-22 in the culture media was measured. Data are from duplicate wells in 1 representative experiment of $2 .{ }^{*} P<0.05$ versus respective PBS control; \# $P<0.05$ versus WT PBS. (A and C) Percent cells in the respective quadrant is indicated. (B, D, and E) Values for IL-23-injected WT and Ccr6 ${ }^{-/-}$mice (E, anti-CD3-stimulated only) were not significantly different. 
A

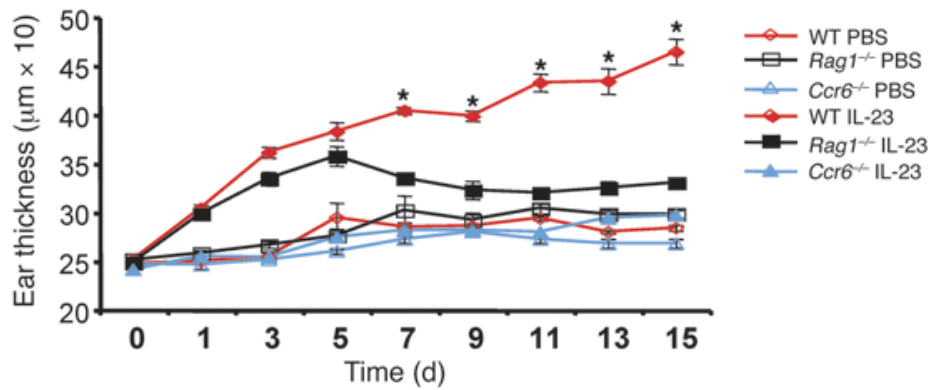

B

Day 5

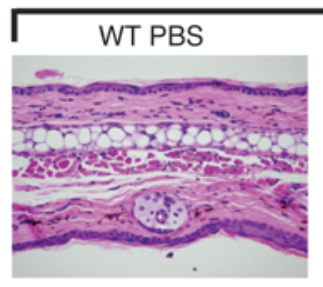

WT IL-23

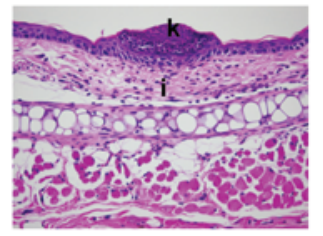

Rag 1 ${ }^{-/}$PBS

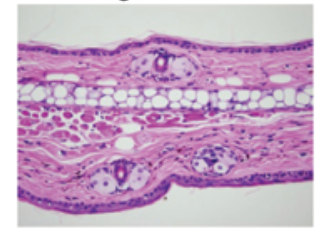

$\operatorname{Rag}^{1^{-/-}}$IL-23

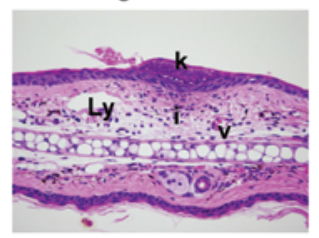

$\mathrm{Ccr6}^{-/} \mathrm{PBS}$

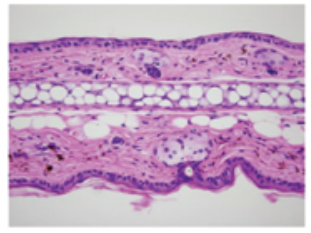

$\mathrm{Ccr6}^{--}$IL-23

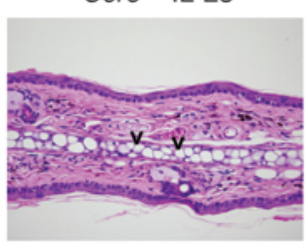

Day 15

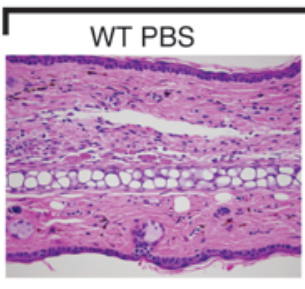

WT IL-23

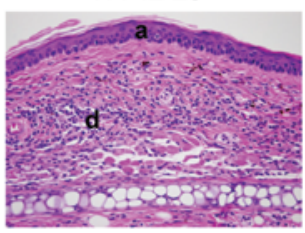

Rag 1-/- PBS

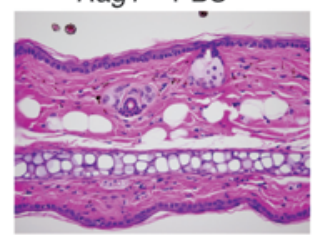

$\operatorname{Rag}^{1-/}$ IL-23

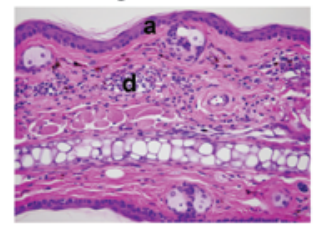

Figure 6

Rag $1^{-/-}$and WT mice show similar initial responses to injections with IL-23. Ears of WT, Rag $1^{-/}$, and Ccr6 ${ }^{-/-}$mice were injected as in Figure 1 . (A) Ear thickness was measured as in Figure 1A. Data are from 2 experiments in at least 7 mice/group, ${ }^{*} P<0.05$, WT versus all other groups. IL-23-injected WT and Rag 1-/- mice were not significantly different at days 0-5. (B) H\&E-stained sections of PBS- or IL-23-injected WT, Rag 1 ${ }^{-/-}$,

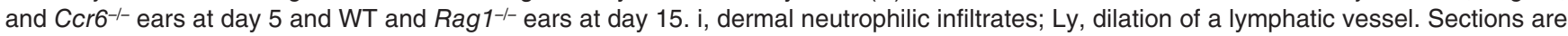
representative of 2 experiments. Original magnification, $\times 400$.

was not increased, after IL-23 injections; moreover, expression did not differ between $\mathrm{Ccr}^{-/-}$and WT mice (data not shown). Together, these data demonstrate that although $\mathrm{Crr}^{-/-}$ears had more Th17 cells at baseline, there were no significant differences between day-15, IL-23-injected $\mathrm{Ccr}^{-/-}$and WT ears with respect to $I l 17 a$ and $I l 17 f$ mRNA levels or the number of T cells capable of producing IL-17A and IL-22.

Rag $1^{-/-}$mice initially show WT responses to IL-23 injection, including IL-22 induction. The discordance between Il22 mRNA level, on the one hand, and Th17/IL-22-producing cell numbers and levels of $I l 17 a$ and Il17f mRNA, on the other, suggested that $\mathrm{CD} 4^{+} \mathrm{T}$ cells might not be the principal source of IL-22 in the IL-23-injected ears. We investigated this possibility by comparing the responses of Rag $1^{-/-}$and WT mice. As shown in Figure 6A, the IL-23-injected Rag $1^{-/-}$and WT ears swelled similarly until day 5, after which ear thickness in the $\operatorname{Rag}^{-/-}$mice decreased toward the baseline values of PBS-injected control and $\mathrm{Ccr}^{-/-}$ears. At day 5, tissue sections from IL-23-injected ears of both WT and Rag $1^{-/-}$mice showed focal hyperparakeratosis and dilated dermal capillaries with mild acanthosis and dermal inflammation (Figure 6B). Particularly striking were the multiple intracorneal pustules, which were much reduced in day-15 ears and rarely seen in $\mathrm{Crr}^{-/-}$ears (Figure 6B and Supplemental Figure 2). By day 15, acanthosis and dermal inflammation increased in IL-23-injected WT ears, with less pronounced changes observed in $\operatorname{Rag} 1^{-/-}$ears (Figure 6B).
Consistent with the importance of IL-22 in the skin pathology, levels of IL-22 in the ears correlated with ear thickness and histology. At day 5, Il22 mRNA was elevated in IL-23-injected Rag1-/- ears, close to the level seen in WT ears and significantly higher than that in $\mathrm{Crr6}^{-/-}$ears, while by day 15, Il22 mRNA levels in Rag1-/- ears had fallen substantially (Figure 7A). These data demonstrate that $\mathrm{T}$ cells are not required initially for either psoriasiform inflammation or local production of IL-22 induced by IL-23 injections. In the absence of $\mathrm{T}$ cells, however, both the inflammatory changes and the elevated levels of IL-22 subsequently diminished, despite continued injections of IL-23.

For Il17a and Ill7f mRNA, Rag1 1/- ears showed low levels at days 5 and 15 (Figure 7, B and C). Similar to our results shown above, Il17a and Il17f mRNA levels were comparable in IL-23-injected WT and $\mathrm{Crr}^{-/-}$ears at day 15. At day 5, however, IL-23-injected $\mathrm{Crr}^{-/-}$ears contained amounts of Il17a and Il17f mRNA that were similar to the level in agg $^{1^{-/}}$ears and much less than that in WT ears. We conclude that T cells are the principal source of IL-17A and IL-17F in the IL-23-injected ears, and that despite Th17 cell numbers similar to or higher than WT levels, the $\mathrm{Crr}^{-/-}$mice show a delay in the induction of IL-17A and IL-17F - along with a consistent defect in induction of IL-22 - in response to the IL-23 injections. Unlike Il22 mRNA levels, $I l 17 a$ and $I l 17 f$ mRNA levels did not correlate with psoriasiform pathology, since they could be low in ears with substan- 

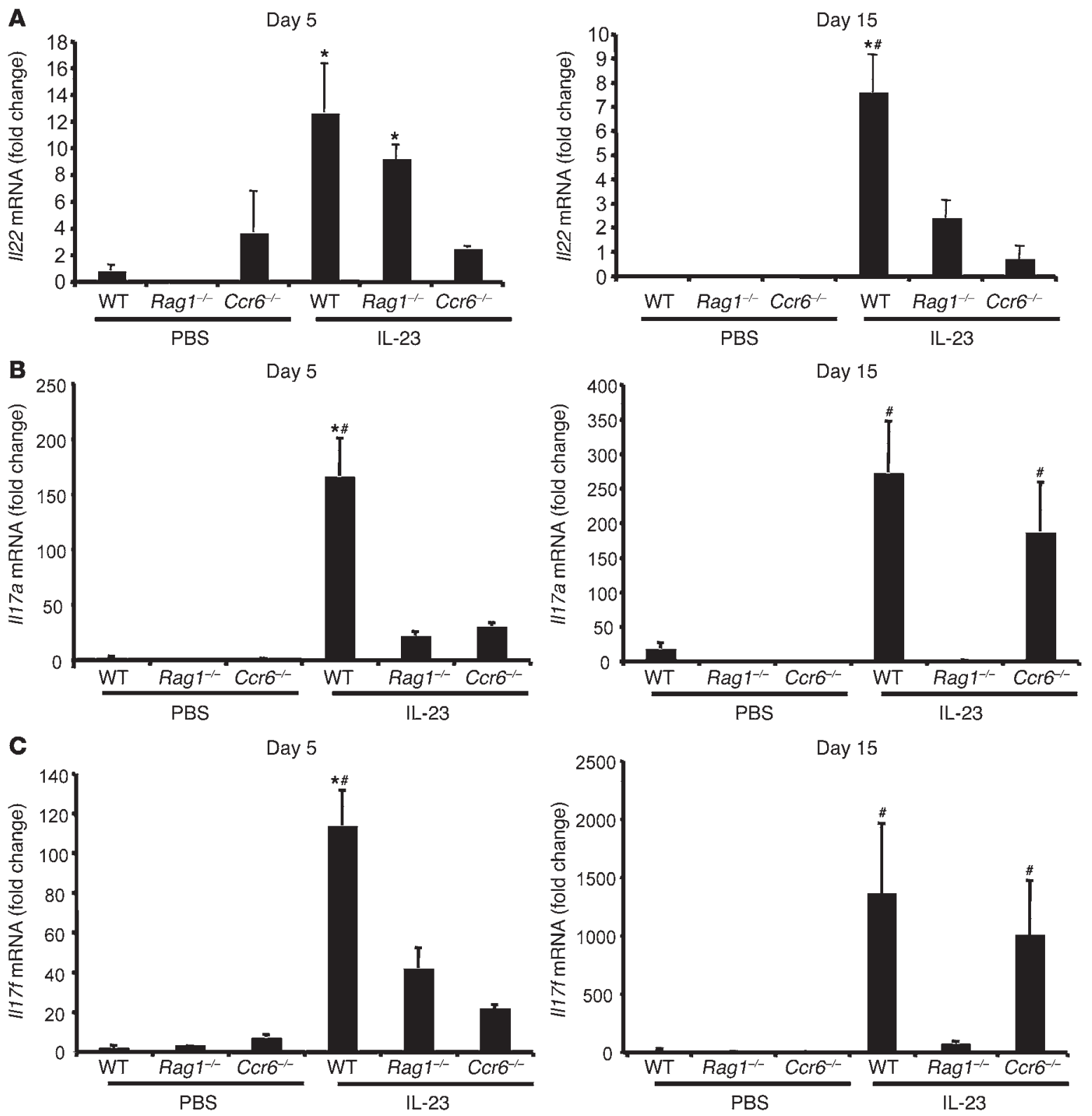

Figure 7

II22 mRNA correlates with IL-23-induced inflammation, but not with I/17a and I/17f mRNA, and is produced in T cell-independent and T celldependent phases. (A-C) Ears were injected as in Figure 1, and mRNAs for II22 (A), I/17a (B), I/17f (C), and Gapdh were measured at days 5 and 15 by real-time RT-PCR. Data are Gapdh-normalized fold changes versus the PBS-injected sample with the greatest $\Delta \mathrm{Ct}$, from 3 mice/group in 1 representative experiment of 2 . Note that values cannot be compared between plots. ${ }^{*} P<0.05$ vs. IL-23 Ccr6 ${ }^{-/-}$; $P<0.05$ vs. IL-23 Rag ${ }^{-1-}$. Other pairwise comparisons between the IL-23-injected groups did not yield significant differences.

tial pathology (e.g., Rag1 $1^{-/-}$mice at day 5) and high in ears with few changes (e.g., $\mathrm{Crr6}^{-/-}$mice at day 15).

\section{Discussion}

Our principal finding is that CCR6 was required for the changes induced in mouse skin by intradermal injection of IL-23. The importance of our findings depends on the relevance of the model for understanding at least some components of human disease. An increasing body of data from both mouse (9-11) and human studies (66) suggests a role for IL-23 in autoimmune disorders. In psoriasis, the most compelling evidence includes genetic data that link both IL-23 and its receptor to disease risk (29-32) and clinical trials suggesting that neutralizing the 40 chain of IL- 23 and IL- 12 is an effective treatment (33-35). Th17 cells constitute the effector population driven by IL-23, and evidence from human studies suggests that IL-22 is a key Th17 cytokine in psoriasis $(40,42,43)$. Moreover, experiments in mice have established a direct connection between IL-23 and the production of IL-22 by both T cells and non-T cells (38, 67-69). Together, the data provide strong support for using the IL-23 injection model in mice, in spite of some clear limitations $(37,70)$. 
A possible link between CCR6 and psoriasiform inflammation was suggested by data on expression of CCR6 and CCL20 in psoriatic skin $(53,56,71)$ and by the observation that IL-17A- and IL-22-producing cells cloned and expanded from psoriatic skin expressed CCR6 (13). The latter finding is consistent with the expression of CCR6 on virtually all human Th17/IL-22-producing T cells (refs. 49-51 and S.P. Singh and J.M. Farber, unpublished observations). A basis for the CCR6/Th17 connection is through RAR-related orphan receptor $\gamma t$ (ROR $\gamma \mathrm{t})$, a critical regulator of Th17 differentiation (72), which has previously been shown to induce expression of CCR6 in mouse and human T cells $(26,52)$. A direct role for CCR6 and CCL20 in Th17 cell-mediated inflammation was suggested by a recent study of a model of rheumatoid arthritis, in which blocking CCR6 decreased disease severity (52).

The changes that we found in IL-23-injected WT ears included ear swelling, intracorneal pustules, acanthosis, and hyperparakeratosis in the epidermis as well as inflammatory infiltrates and dilated capillaries in the dermis. While these effects of intradermal injections with IL-23 have been well described, previous reports have shown results from either early (37) or late (38) in the course of the injections. In experiments using up to 7 daily injections of $1 \mu \mathrm{g}$ IL-23 divided between 2 sites in the back skin, Chan et al. reported intracorneal pustules, hyperparakeratosis, and epidermal thickening that were maximal at day 4 and diminished to varying degrees by day 7 (37). In the present study, using the protocol of Zheng et al. (38), in which ear skin is injected intradermally with $500 \mathrm{ng}$ IL-23 every other day, we found a temporal progression that to our knowledge has not been noted previously, with prominent intracorneal pustules early on (day 5 ) giving way to increasing acanthosis and dermal inflammation (day 15). Taken together, our findings suggest that the evolution in pathology may be related to progression from a $\mathrm{T}$ cell-independent to a $\mathrm{T}$ cell-dependent phase of the IL-23-induced response, as discussed below.

The resistance to pathology in the $\mathrm{Ccr}^{-/-}$mice was associated with a level of Il22 induction that was low relative to the WT mice. Consistent with the importance of the poor Il22 response in limiting inflammation in $\mathrm{Crr}^{-/-}$mice, injecting IL-22 produced a similar degree of acanthosis, accumulation of $\mathrm{CD}^{+} \mathrm{T}$ cells, and other inflammatory changes in both $\mathrm{Ccr6}^{-1-}$ and WT ears. These results notwithstanding, the lack of IL-22 did not appear to be the only salutary effect of CCR6 deficiency in this model. While deficiency in CCR6 prevented almost all of the histological changes induced by IL-23, the absence of IL-22 was not sufficient to block the effects of IL-23 completely (38), nor were injections of IL-22 alone able to recapitulate fully the magnitude of the IL-23 effects (present study).

The lack of Il22 expression in IL-23-injected $\mathrm{Crr}^{-/-}$ears was not due to any inherent defect in the ability of CCR6-deficient cells to differentiate appropriately, and we presumed that any role for CCR6 in this model would be through effects on Th17 cell migration at the inflammatory site. However, evaluation of the day-15 ears for Th17/IL-22-producing T cells, which were analyzed after activation ex vivo, also provided no explanation for the low levels of Il22 mRNA in $\mathrm{Crr6}^{-/-}$mice. Although Th17 cells in IL-23-injected WT ears expressed CCR6, we found no differences in the IL-23injected $\mathrm{Ccr6}^{-/-}$versus WT ears with regard to Il17a or Il17f mRNA level, number of cells that could be activated to produce IL-17A or IL-22, or IL-22 secretion after stimulation with anti-CD3 ex vivo.

Our failure to find deficits in the Th17/IL-22-producing T cells in the $\mathrm{Crr6}^{-/-}$mice led us to examine the role of T cells in the model by using Rag1 $1^{-/-}$mice. At day 5, IL-23-injected Rag $1^{-/-}$and WT ears showed equivalent degrees of swelling, with focal hyperparakeratosis, dilated dermal capillaries, mild acanthosis and dermal inflammation, and intracorneal pustules. After day 5, while changes in the WT mice progressed, those in the $\mathrm{Rag} 1^{-/-}$mice began to resolve. Relative Il22 mRNA levels in the ears correlated well with pathology: in WT mice, persistently high; in $\mathrm{Ccr6}^{-/-}$mice, persistently low; in Rag $1^{-/-}$mice, high at day 5 and diminished at day 15 . The $R a g 1^{-/-}$data provided a way to reconcile, at least in part, our findings that the $\mathrm{Crr}^{-/-}$mice showed little induction of Il22 despite WT-level numbers of Th17/IL-22-producing T cells. A critical component of the IL-23-induced pathology was an early, CCR6-dependent increase in IL-22 from a non-T cell source.

The experiments with Rag1-/- mice demonstrated not only the early, T cell-independent component to the IL-23-induced changes, but also a later, T cell-dependent component. An associated defect in $\mathrm{T}$ (Th17) cell responses within the $\mathrm{Ccr}^{-/-}$ears was in fact revealed in the cytokine profiles. Rag1 $1^{-/}$mice showed consistently low levels of Il17a and Il17f mRNA compared with WT mice, in line with T cells being an important source of these cytokines (73) and suggesting that levels of Il17 $a$ and Il17f mRNA in the ears served as a readout of Th17 cell activity. Although by day 15, levels of these mRNAs were not markedly lower in the IL-23-injected ears of $\mathrm{Ccr}^{-/-}$versus WT mice, at day 5, Ill7 $a$ and Ill7f mRNA induction in $\mathrm{Ccr}^{-/-}$mice was much reduced compared with WT mice. These findings suggest that although we were unable to detect deficiencies in Th17/IL-22producing T cells from IL-23-injected $\mathrm{Crr}^{-/}$ears when analyzed ex vivo, Th17 cells in the $\mathrm{Crr}^{-/-}$and WT ears were not responding to IL-23 injections equivalently in situ. Taken together, our data suggest that direct effects of IL-23 on Th17/IL-22-producing T cells in the skin are not sufficient to produce psoriasiform pathology - otherwise, such changes would have been seen in the ears of $\mathrm{Crr6}^{-/-}$mice, which have normal (or higher) numbers of Th17 cells. Rather, IL-23 initiated a T cell-independent inflammatory process, which resulted in the production of IL-22 and early changes in the skin and was required for optimal activation of Th17 cells (and perhaps other $\mathrm{T}$ cells) and the sustained, $\mathrm{T}$ cell-dependent inflammation observed in the WT mice. A parsimonious explanation for our findings is that, by preventing the early, $\mathrm{T}$ cell-independent events, the absence of CCR 6 also blocked subsequent $T$ cell activation and the full development of skin pathology, even though the relevant $\mathrm{T}$ cell subsets were present.

Although Th17 cells were identified in control and IL-23-injected ears, in both WT and $\mathrm{Crr}^{-/-}$mice, we only found T cells capable of making IL-22 in IL-23-injected ears. Together with the fact that the IL-23-injected $\mathrm{Crr6}^{-/-}$ears showed little change in the numbers of $\mathrm{T} / \mathrm{Th} 17$ cells, this observation raises the possibility that one effect of IL-23 was to make Th17 cells within the ear IL-22 capable. Regardless of whether these $T$ cells were a significant source of IL-22 in WT ears, injected IL-23 was clearly not sufficient to induce enough IL-22 from T cell or non-T cell sources to produce pathology in the $\mathrm{Crr6}^{-1-}$ mice.

Although Il17a and Il17f mRNA levels were much lower in the IL-23-injected ears of $\mathrm{Crr}^{-/-}$compared with WT mice at day 5, we have no evidence that the failure to produce IL-17A and/or IL-17F early on was important in preventing inflammatory changes. IL-17A and/or IL-17F might have been presumed to have a role particularly in forming the early intracorneal pustules, given their roles in recruiting neutrophils and the ability of IL-17A to induce neutrophil-attracting chemokines in human keratinocytes (74). However, 
we found no simple correlation between the pustules and these cytokines, as $I l 17 a$ and $I l 17 f$ mRNA levels were not markedly differ-

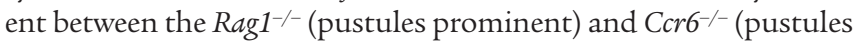
uncommon) mice at day 5. In fact, we generally found that $I l 17 a$ and Il17f mRNA levels did not correlate well with pathology, consistent with earlier work showing that blocking IL-17A had no effect on epidermal hyperplasia induced by 4 daily injections of IL-23 and that intradermal injections of IL-17A failed to cause the epidermal hyperplasia seen with IL-23 (37). An auxiliary role for IL-17A and IL-17F in the IL-23-induced changes cannot be excluded.

CCR6 is expressed not only on Th17 cells, but also on a subset of mouse and human CD25+ Tregs that produce IL-10 (75). Since the $\mathrm{Cr}^{-/-}$mice showed an absence of, rather than an exacerbation of, inflammation after IL-23 injection, a defect in Treg recruitment could not explain our findings. However, we considered the possibility that CCL20 might act through CCR6 as an inhibitor of Treg function. In fact, CCL20 showed no such activity when analyzed in Treg-dependent suppressor assays in vitro (data not shown). In addition, we did not detect elevated levels of Il10 mRNA in IL-23-injected $\mathrm{Crr}^{-/-}$or WT ears (data not shown). These data suggest that the absence of psoriasiform changes in the IL-23-injected $\mathrm{Crr}^{-1-}$ mice was not related to effects on Tregs. A role for CCR6 on Tregs may be reflected in the higher number of Th17 cells that we found in the PBS-injected ears, as well as in the spleens (data not shown), of $\mathrm{Crr6}^{-/-}$compared with WT mice. Higher numbers of Th17 cells in $\mathrm{Ccr}^{-1-}$ mice were also recently reported by others, who speculated that this increase was the result of a failure of CCL20-mediated colocalization of $C C R 6^{+}$Tregs and differentiating CCR $6^{+}$effectors, leading to diminished suppression of Th17 differentiation (65).

Important unresolved and interrelated issues are the identities of the cells mediating early inflammation and IL-22 production, the precise ways in which their roles in the response depend on CCR6, and the relationships between the early and late phases of the response. Principal candidates for non-T cells mediating the early response are subsets of dendritic cells and/or NK cells. Dendritic cells are proposed as important contributors to psoriasis (2, 76) and have been found to produce IL-22 in response to IL-23 (69). Moreover, there is a demonstrated role for CCR6 in dendritic cell recruitment to the inflamed skin $(77,78)$. It is noteworthy that the reports of CCR6-dependent trafficking of skin dendritic cells (77, 78) did not demonstrate CCR6 expression on these cells. Although we found increased numbers of dendritic cells in the IL-23-injected ears of WT mice, but not $\mathrm{Crr}^{-/-}$mice, we were also unable to detect CCR 6 on the $\mathrm{CD} 11 \mathrm{c}^{+} \mathrm{CD} 11 \mathrm{~b}^{+}$cells from the ears (data not shown); thus, the role of CCR6 in recruitment of dendritic cells to the IL-23-injected ears may have been indirect. Whatever the role for CCR6 on dendritic cells under inflammatory conditions, we found no difference in the number of $\mathrm{CD} 11 \mathrm{c}^{+} \mathrm{CD} 11 \mathrm{~b}^{+}$cells in nonmanipulated ears in $\mathrm{Crr}^{-/-}$and WT mice, nor did we find differences between these mice in the number of Langerhans cells in epidermal sheets (data not shown), consistent with published data $(58,78)$. Very recent reports have described cells with NK cell markers that are an innate source of IL-22, so-called "NK-22" cells, which express - and whose development depends on - ROR $\gamma t$ (79-82). In humans, these cells express CCR6 and have been found in inflamed skin (79). In mice, at least under homeostatic conditions, the equivalent subset appears confined to the gut (80), and we did not detect these cells in the noninjected ears (data not shown). It will be of interest to investigate whether these NK-22 cells are found in extraintestinal sites in mice during inflammatory responses.
Our present findings showed an expanded role for CCR6 in IL-23related responses, one that was not limited to effects on Th17 cell trafficking. Such a broad role makes CCR6 an appealing target for therapies against the lengthening list of diseases mediated by Th17 cells. The recent approval of a chemokine receptor antagonist for clinical use (83) provides an encouraging precedent and suggests that developing drugs against additional chemokine receptors is a realistic goal. The accumulated mouse and human data suggest that blocking a chemokine receptor such as CCR6 is likely to cause less overall immunosuppression than therapies that inhibit pleiotropic immune modulators.

\section{Methods}

Mice. C57BL/6 WT mice were purchased from the Division of Cancer Therapy, NCI, NIH; from Taconic; or from The Jackson Laboratory. Rag1 $1^{-1-}$ mice were purchased from The Jackson Laboratory. C57BL/6 $\mathrm{Ccr}^{-/}$mice were derived as described below. All mice were housed in sterile cages in pathogen-free conditions and used at 8-20 weeks of age. Animal protocols were approved by the Animal Care and Use Committee of the NIAID, NIH.

Targeting of the mouse Ccr6 gene and creation of mouse lines. The mouse Ccr6 gene was isolated by using a human CCR6 cDNA fragment to probe a 129/SvJ mouse genomic DNA library in Lambda Fix II (Stratagene), generated and provided by S.-J. Lee (Johns Hopkins University School of Medicine, Baltimore, Maryland, USA). A BamHI fragment of the mouse Crr6 gene corresponding to positions 73,2125-73,8664 in GenBank record NT_039638 which includes the entire Crr6 ORF - was sequenced and used for producing fragments for gene targeting. Details of $\mathrm{Crr}^{--}$mouse production are shown in Supplemental Figure 1. The targeting DNA was constructed on the pPNT backbone (84) with the Ccr6 fragments flanking an insertion cassette containing EGFP (taken from pEGFP; Clontech) downstream of an internal ribosome entry site [taken from pCITE-2a(+); Novagen] and followed by the small $t$ antigen intron and early region polyadenylylation sequence of SV40 (taken from PMSXND; provided by S.-J. Lee; ref. 85) and a neomycin resistance gene flanked by loxP sites (taken from pL2-neo ${ }^{\text {r }}$; provided by H. Gu, NIAID, NIH). The pPNT-muccr6 targeting vector was linearized using the unique NotI site and transfected into R1 ES cells, followed by selection with G418 and ganciclovir. DNAs from 220 G418- and ganciclovir-resistant colonies were digested with Bam HI and screened by Southern blot analysis using a 515-bp fragment from sequences upstream of the $5^{\prime}$ recombination fragment. Of these $220 \mathrm{ES}$ cell colonies, 8 yielded a Bam HI fragment of approximately $3 \mathrm{~kb}$, the predicted size for the targeted allele. Following additional analysis by Southern blotting to rule out multiple insertions and assure proper structure at the targeted site, ES cells were chosen for injection into C57BL/6 blastocysts. The neomycin resistance gene and its associated promoter were removed by crossing chimeras with mice containing the EIIaCre transgene in the C57BL/ 6 background, and offspring were screened for loss of both neo and EIIaCre. Mice were backcrossed to C57BL/ 6 at least 8 times and intercrossed to yield breeders that were used to produce mice for experiments.

Analysis of CCR6 expression and function in $\mathrm{Ccr}^{-/-}$mice. Resting B cells were purified from mouse splenocytes by negative magnetic selection using CD43 MicroBeads per the manufacturer's instructions (Miltenyi Biotec). $B$ cells were either used fresh or stimulated for 48 hours with $10 \mu \mathrm{g} / \mathrm{ml}$ goat anti-mouse $\operatorname{IgM~F}\left(\mathrm{ab}^{\prime}\right)_{2}$ from ICN Biomedicals. Analysis of CCR6 surface expression was analyzed by flow cytometry, as described below. For assaying chemotaxis, B cells were loaded into transwell inserts with $5-\mu \mathrm{m}$ pores (Costar) sitting in wells containing chemotaxis buffer, which consisted of RPMI 1640 (Invitrogen) supplemented with $20 \mu \mathrm{M}$ HEPES (Invitrogen) and $0.5 \% \mathrm{BSA}$ (Invitrogen), for 30 minutes at $37^{\circ} \mathrm{C}$ in $5 \% \mathrm{CO}_{2}$. Inserts were moved to wells containing chemotaxis media alone or supplemented with $1 \mu \mathrm{g} / \mathrm{ml}$ mouse CCL20 (PeproTech) or mouse CXCL12 (PeproTech) and 
incubated for 3 hours. Migrated cells were counted using a flow cytometer after adding a known number of fluorescent counting beads (see below).

Intradermal cytokine injections. We performed intradermal injection of $20 \mu \mathrm{l}$ PBS, either alone or containing 500 ng recombinant mouse IL-23 or IL-22 (eBiosience), into the ears of anesthetized mice using a 30-gauge needle every other day for 16 days. Ear thickness was measured before injection on day 0 and thereafter on days without injections. Ear measurements were made at the center of the ears using a G-1A dial thickness gauge (Peacock). All measurements were performed blinded. At various times, mice were euthanized, and tissue was collected.

Processing of ear skin, lymph nodes, and splenocytes for flow cytometry and ex vivo stimulation. Injected ears were collected, and cell suspensions from individual ears were prepared as previously described (86). Briefly, after collection of ears, ventral and dorsal dermal sheets were separated from cartilage and incubated for 45 minutes at $37^{\circ} \mathrm{C}$ with dermal side down in RPMI 1640 containing 0.28 Wunsch units/ml of Liberase CI blendzyme (Roche Diagnostics). Next, the ear sheets of individual animals were mechanically separated for 5 minutes using a Medimachine tissue disruptor according to the manufacturer's instructions (BD Biosciences - Pharmingen), with complete RPMI supplemented with 0.05\% DNAse (Sigma-Aldrich) as a buffer. Complete RPMI contained RPMI 1640 supplemented with $10 \%$ fetal bovine serum (Gemini Bio-Products), 20 mM HEPES, 55 M 2-mercapoethanol, $1 \mathrm{mM}$ sodium pyruvate, $2 \mathrm{mM}$ L-glutamine, $0.1 \mathrm{mM}$ nonessential amino acids, and $100 \mathrm{U} / \mathrm{ml}$ penicillin and streptomycin (all from Invitrogen). Lymph nodes or spleens were mechanically disrupted using a syringe plunger in complete RPMI. Cells were filtered through $100-\mu \mathrm{m}$ nylon mesh and washed before activation and/or staining.

Histopathological analysis and immunofluorescence microscopy. Sections from paraffin-embedded whole ears $(7 \mu \mathrm{m})$ were prepared by American Histolabs or HistoServe Inc. and stained with H\&E. Staining for CCL20 was done using frozen $7-\mu \mathrm{m}$ sections of whole mouse ears; sections were airdried after 5 minutes of fixation in ice-cold acetone, blocked for 1 hour at room temperature with $5 \%$ goat serum in PBS containing 3\% skim milk, and incubated with rat anti-mouse CCL20 (clone 114906; R\&D Systems) or rat $\mathrm{IgG}_{1}$ isotype control antibody (eBioscience) for 1 hour at room temperature. After washing in PBS, the sections were incubated for 30 minutes at room temperature with an Alexa Fluor 488-conjugated goat-anti-rat IgG (Invitrogen), then washed in PBS and mounted using ProLong Gold antifade reagent with DAPI nuclear stain (Invitrogen). Images were acquired at $\times 400$ magnification using a Carl Zeiss microscope and AxioVision software (release 4.5; Zeiss). H\&E images were captured using a DP71 digital camera (Olympus) attached to an Olympus BX41 microscope.

RT-PCR, quantification, and display. Extraction of RNA from whole ears was performed using a Qiagen RNeasy Kit according to the manufacturer's instructions. RNA extraction from cultured cells was performed using TRIzOL reagent according to the manufacturer's instructions (Invitrogen). We used Platinum Quantitative RT-PCR ThermoScript One-Step System (Invitrogen) to perform one-step RT-PCR. The following primers and probes were purchased from Applied Biosystems: GAPDH (catalog no. Mm99999915_g1), IL-17A (catalog no. Mm00439619_m1), IL-17F (cata$\log$ no. Mm00521423_m1), CCL20 (catalog no. Mm01268754_m1), and IL-22, which was a custom construct using previously described sequences (38). The reactions were run on an Applied Biosystems 7900HT system using the standard protocol provided by Invitrogen. Data were represented as fold differences relative to control/reference samples. Fold difference was calculated by the $2^{-\Delta \Delta \mathrm{Ct}}$ method, where $\Delta \mathrm{Ct}=\mathrm{Ct}_{\text {cytokine} / \text { chemokine }}-\mathrm{Ct}_{\mathrm{GAPDH}}$ and $\Delta \Delta \mathrm{Ct}=\Delta \mathrm{C} \mathrm{t}_{\text {induced }}-\Delta \mathrm{Ct} \mathrm{t}_{\text {reference. }} . \Delta \mathrm{Ct}_{\text {reference }}$ was chosen as the PBS-injected or other reference sample with the greatest $\Delta \mathrm{Ct}$ for each plot.

Flow cytometry and intracellular staining. Monocolonal fluorescent antibodies against mouse CD45, CD3, CD4, CD8, $\gamma \delta$ TCR, NK1.1, CD11b,
B220, CD11c, CD25, CD62L, and CD44 as well as streptavidin-PE were purchased from BD Biosciences. Antibodies against IL-17A, Ly-6G, and F4/80 were purchased from eBioscience. Antibodies against TCR $\beta$, CCR6, and IL-22 were purchased from Biolegend, R\&D Systems, and Antigenix, respectively. Propidium iodide (PI) was purchased from Invitrogen. Flow cytometry was performed on single-cell suspensions of ear skin (see above) or lymph node cells. For immunotyping of cells, dead cells were eliminated on the basis of positive PI staining. $\mathrm{CD} 4^{+} \mathrm{T}$ cells were identified by their scatter profile and as $\mathrm{PI}-\mathrm{CD} 45^{+} \mathrm{CD} 3{ }^{+} \mathrm{CD} 4{ }^{+}$. For some samples, CCR6 expression was also evaluated on $\mathrm{CD}^{+}{ }^{+} \mathrm{T}$ cells. Dendritic cells were identified by their scatter profile and as $\mathrm{PI}^{-} \mathrm{CD} 45^{+} \mathrm{CD} 3^{-} \mathrm{B} 220^{-} \mathrm{CD} 11 \mathrm{c}^{+} \mathrm{CD} 11 \mathrm{~b}^{+}$. Intracellular staining for IL-17A was done after activating cells for 6 hours with Leukocyte Activation Cocktail with GolgiPlug (BD Biosciences - Pharmingen). Cells were then fixed and permeabilized using the Cytofix/Cytoperm Plus Kit according to the manufacturer's instructions (BD Biosciences). For intracellular staining, the same surface markers were used to identify $\mathrm{CD}^{+} \mathrm{T}$ cells, and PI was omitted. Absolute numbers of cells were calculated by adding a known number of fluorescent counting beads (Spherotech) to each of the samples. The ratio of beads counted on the flow cytometer to the number of beads added to the sample was determined and used to calculate the absolute numbers in the samples for cells of a given immunophenotype. All samples were analyzed on an LSR II System flow cytometer (BD Biosciences), and the data were analyzed using FlowJo software (version 8.2; Tree Star).

Sorting naive cells and differentiation of Th17 cells in vitro. For the sorting of naive $\mathrm{CD} 4^{+} \mathrm{T}$ cells, splenocytes and lymph node cells were harvested from nonmanipulated mice, and $\mathrm{CD} 4^{+} \mathrm{T}$ cells were first enriched using the $\mathrm{CD} 4^{+}$ negative selection kit from Miltenyi Biotec and their autoMACS machine, following the manufacturer's instructions. Naive cells were purified by cell sorting based on the criterion $\mathrm{CD} 4^{+} \mathrm{CD} 25^{-} \mathrm{CD} 62 \mathrm{~L}^{+} \mathrm{CD} 44^{\text {lo }}$. The sorted cells were stimulated with $10 \mu \mathrm{g} / \mathrm{ml}$ plate-bound hamster anti-mouse CD3E (clone 145-2C11; R\&D Systems) and $1 \mu \mathrm{g} / \mathrm{ml}$ soluble hamster antimouse CD28 (BD Biosciences) for 3 days under nonpolarizing or Th17polarizing conditions in complete RPMI. For nonpolarizing conditions, complete RPMI was supplemented with $10 \mu \mathrm{g} / \mathrm{ml}$ rat anti-mouse IFN- $\gamma$ (BD Biosciences), $10 \mu \mathrm{g} / \mathrm{ml}$ rat anti-mouse IL-4 (BD Biosciences), $10 \mathrm{ng} / \mathrm{ml}$ mouse IL-2 (R\&D Systems), and $10 \mathrm{ng} / \mathrm{ml}$ mouse TGF- $\beta 1$ (Sigma-Aldrich). For Th17 conditions, complete RPMI was supplemented with $10 \mu \mathrm{g} / \mathrm{ml}$ rat anti-mouse IFN- $\gamma, 10 \mu \mathrm{g} / \mathrm{ml}$ rat anti-mouse IL-4, $10 \mathrm{ng} / \mathrm{ml}$ mouse IL-23 (eBiosciences), $20 \mathrm{ng} / \mathrm{ml}$ mouse IL-6 (R\&D Systems), $10 \mathrm{ng} / \mathrm{ml}$ mouse TGF- $\beta 1,5 \mathrm{ng} / \mathrm{ml}$ mouse IL- $1 \beta$ (R\&D Systems), and $5 \mathrm{ng} / \mathrm{ml}$ mouse TNF- $\alpha$ (R\&D Systems). After 3 days of stimulation, the cells were washed and resuspended in fresh media supplemented as above per the respective polarizing condition, but without anti-CD3 or anti-CD28. After a total of 7 days in culture, the cells were harvested and stimulated with $20 \mathrm{ng} / \mathrm{ml}$ PMA and $1 \mu \mathrm{M}$ ionomycin for 6 hours before preparing RNA.

Measuring $I L-22$ produced by cells stimulated ex vivo with $I L-23$ or anti-CD 3 . For unfractionated splenocytes, cells were cultured at $2 \times 10^{6} \mathrm{cells} / \mathrm{ml}$ in complete RPMI supplemented with $100 \mathrm{ng} / \mathrm{ml}$ mouse IL-23 (eBioscience) for 12 hours at $37^{\circ} \mathrm{C}$. For stimulating cells from the ears, single-cell suspensions were pooled from multiple ears and then divided so that cells equivalent to a single ear were cultured per well in a 24-well plate. Whole-ear suspensions were stimulated with $10 \mu \mathrm{g} / \mathrm{ml}$ soluble hamster anti-mouse $\mathrm{CD} 3 \varepsilon$ for 12 hours at $37^{\circ} \mathrm{C}$. Supernatants were harvested and analyzed using a mouse IL-22 ELISA Construction Kit (Antigenix) according to the manufacturer's instructions. We used 3,3',5,5'-tetramethylbenzidine as a chromogen, detected with a microplate reader set at $450 \mathrm{~nm}$.

Statistics. All quantitative data are shown as mean \pm SEM unless otherwise indicated. All samples were compared using 2-tailed, unpaired Student's $t$ test. A $P$ value less than 0.05 was considered significant. 


\section{Acknowledgments}

We are grateful to Se-Jin Lee for providing materials, Hua Gu for consultations, Eileen O'Hara and Hong Duc V. Dang for expert technical assistance in preparing the pPNT-muccr6 targeting vector, and Saeko Nomura for blastocyst injections. A.S. Lonsdorf was supported by a NIH/Deutsche Forschungsgemeinschaft Research Career Transition Award. This research was supported by the Intramural Research Program, NIAID, NCI, and NICHD, NIH.

Received for publication September 8, 2008, and accepted in revised form May 6, 2009.
Bethesda, Maryland 20892, USA. Phone: (301) 402-4910; Fax: (301) 402-4369; E-mail: jfarber@niaid.nih.gov.

Sam T. Hwang's present address is: Department of Dermatology, Medical College of Wisconsin, Froedtert Clinic East, Milwaukee, Wisconsin, USA.

Anke S. Lonsdorf's present address is: Department of Dermatology, University Hospital Heidelberg, Heidelberg, Germany.

Aiko-Konno Shirakawa's present address is: Kinki University School of Medicine, Osaka-Sayama, Osaka, Japan.

Address correspondence to: Joshua M. Farber, Laboratory of Fang Liao's present address is: Institute of Biomedical Sciences, Molecular Immunology, NIAID, NIH, Building 10, Room 11N-112, Academia Sinica, Taipei, Taiwan.

1. Schon, M.P., and Boehncke, W.H. 2005. Psoriasis. N. Engl. J. Med. 352:1899-1912.

2. Lowes, M.A., Bowcock, A.M., and Krueger, J.G. 2007. Pathogenesis and therapy of psoriasis. Nature. 445:866-873

3. Bowcock, A.M., and Krueger, J.G. 2005. Getting under the skin: the immunogenetics of psoriasis. Nat. Rev. Immunol. 5:699-711.

4. Nickoloff, B.J., and Nestle, F.O. 2004. Recent insights into the immunopathogenesis of psoriasis provide new therapeutic opportunities. J. Clin. Invest. 113:1664-1675.

5. Gottlieb, A.B., et al. 2003. A randomized trial of etanercept as monotherapy for psoriasis. Arch. Dermatol. 139:1627-1632.

6. Papp, K.A., et al. 2005. A global phase III randomized controlled trial of etanercept in psoriasis: safety, efficacy, and effect of dose reduction. $\mathrm{Br}$. J. Dermatol. 152:1304-1312.

7. Chaudhari, U., et al. 2001. Efficacy and safety of infliximab monotherapy for plaque-type psoriasis: a randomised trial. Lancet. 357:1842-1847.

8. Reich, K., et al. 2005. Infliximab induction and maintenance therapy for moderate-to-severe psoriasis: a phase III, multicentre, double-blind trial. Lancet. 366:1367-1374.

9. Cua, D.J., et al. 2003. Interleukin-23 rather than interleukin-12 is the critical cytokine for autoimmune inflammation of the brain. Nature. 421:744-748.

10. Murphy, C.A., et al. 2003. Divergent pro- and antiinflammatory roles for IL-23 and IL-12 in joint autoimmune inflammation. J. Exp. Med. 198:1951-1957.

11. Langrish, C.L., et al. 2005. IL-23 drives a pathogenic $T$ cell population that induces autoimmune inflammation. J. Exp. Med. 201:233-240.

12. Blauvelt, A. 2008. T-helper 17 cells in psoriatic plaques and additional genetic links between IL-23 and psoriasis. J. Invest. Dermatol. 128:1064-1067.

13. Pene, J., et al. 2008. Chronically inflamed human tissues are infiltrated by highly differentiated Th17 lymphocytes. J. Immunol. 180:7423-7430.

14. Bettelli, E., Korn, T., and Kuchroo, V.K. 2007. Th17: the third member of the effector T cell trilogy. Curr. Opin. Immunol. 19:652-657.

15. Ouyang, W., Kolls, J.K., and Zheng, Y. 2008. The biological functions of $\mathrm{T}$ helper 17 cell effector cytokines in inflammation. Immunity. 28:454-467.

16. Lowes, M.A., et al. 2008. Psoriasis Vulgaris Lesions Contain Discrete Populations of Th1 and Th17 T Cells. J. Invest. Dermatol. 128:1207-1211.

17. Guttman-Yassky, E., et al. 2008. Blockade of CD11a by efalizumab in psoriasis patients induces a unique state of T-cell hyporesponsiveness. J. Invest. Dermatol. 128:1182-1191.

18. van Beelen, A.J., Teunissen, M.B., Kapsenberg, M.L., and de Jong, E.C. 2007. Interleukin-17 in inflam- matory skin disorders. Curr. Opin. Allergy Clin. Immunol. 7:374-381.

19. Fitch, E., Harper, E., Skorcheva, I., Kurtz, S.E., and Blauvelt, A. 2007. Pathophysiology of psoriasis: recent advances on IL-23 and Th17 cytokines. Curr. Rheumatol. Rep. 9:461-467.

20. Lee, E., et al. 2004. Increased expression of interleukin 23 p 19 and $\mathrm{p} 40$ in lesional skin of patients with psoriasis vulgaris. J. Exp. Med. 199:125-130.

21. Zaba, L.C., et al. 2007. Amelioration of epidermal hyperplasia by TNF inhibition is associated with reduced Th17 responses. J. Exp. Med. 204:3183-3194.

22. Piskin, G., Sylva-Steenland, R.M., Bos, J.D., and Teunissen, M.B. 2006. In vitro and in situ expression of IL-23 by keratinocytes in healthy skin and psoriasis lesions: enhanced expression in psoriatic skin. J. Immunol. 176:1908-1915.

23. Wilson, N.J., et al. 2007. Development, cytokine profile and function of human interleukin 17-producing helper T cells. Nat. Immunol. 8:950-957.

24. Oppmann, B., et al. 2000. Novel p19 protein engages IL-12p40 to form a cytokine, IL-23, with biological activities similar as well as distinct from IL-12. Immunity. 13:715-725.

25. Aggarwal, S., Ghilardi, N., Xie, M.H., de Sauvage, F.J., and Gurney, A.L. 2003. Interleukin-23 promotes a distinct $\mathrm{CD} 4 \mathrm{~T}$ cell activation state characterized by the production of interleukin-17. J. Biol. Chem. 278:1910-1914.

26. Manel, N., Unutmaz, D., and Littman, D.R. 2008. The differentiation of human $\mathrm{T}(\mathrm{H})-17$ cells requires transforming growth factor-beta and induction of the nuclear receptor RORgammat. Nat. Immunol. 9:641-649.

27. Volpe, E., et al. 2008. A critical function for transforming growth factor-beta, interleukin 23 and proinflammatory cytokines in driving and modulating human $\mathrm{T}(\mathrm{H})-17$ responses. Nat. Immunol. 9:650-657.

28. McGeachy, M.J., et al. 2009. The interleukin 23 receptor is essential for the terminal differentiation of interleukin 17-producing effector T helper cells in vivo. Nat. Immunol. 10:314-324.

29. Capon, F., et al. 2007. Sequence variants in the genes for the interleukin-23 receptor (IL23R) and its ligand (IL12B) confer protection against psoriasis. Hum. Genet. 122:201-206.

30. Cargill, M., et al. 2007. A large-scale genetic association study confirms IL12B and leads to the identification of IL23R as psoriasis-risk genes. Am. J. Hum. Genet. 80:273-290.

31. Nair, R.P., et al. 2008. Polymorphisms of the IL12B and IL23R genes are associated with psoriasis. J. Invest. Dermatol. 128:1653-1661.

32. Nair, R.P., et al. 2009. Genome-wide scan reveals association of psoriasis with IL-23 and NF-kappaB pathways. Nat. Genet. 41:199-204.

33. Krueger, G.G., et al. 2007. A human interleukin-
$12 / 23$ monoclonal antibody for the treatment of psoriasis. N. Engl. J. Med. 356:580-592.

34. Leonardi, C.L., et al. 2008. Efficacy and safety of ustekinumab, a human interleukin-12/23 monoclonal antibody, in patients with psoriasis:76week results from a randomised, double-blind, placebo-controlled trial (PHOENIX 1). Lancet. 371:1665-1674.

35. Papp, K.A., et al. 2008. Efficacy and safety of ustekinumab, a human interleukin-12/23 monoclonal antibody, in patients with psoriasis:52week results from a randomised, double-blind, placebo-controlled trial (PHOENIX 2). Lancet. 371:1675-1684.

36. Kopp, T., et al. 2003. IL-23 production by cosecretion of endogenous p 19 and transgenic p40 in keratin 14/p40 transgenic mice: evidence for enhanced cutaneous immunity. J. Immunol. 170:5438-5444.

37. Chan, J.R., et al. 2006. IL-23 stimulates epidermal hyperplasia via TNF and IL-20R2-dependent mechanisms with implications for psoriasis pathogenesis. J. Exp. Med. 203:2577-2587.

38. Zheng, Y., et al. 2007. Interleukin-22, a T(H)17 cytokine, mediates IL-23-induced dermal inflammation and acanthosis. Nature. 445:648-651.

39. Ma, H.L., et al. 2008. IL-22 is required for Th17 cellmediated pathology in a mouse model of psoriasislike skin inflammation. J. Clin. Invest. 118:597-607.

40. Sa, S.M., et al. 2007. The effects of IL-20 subfamily cytokines on reconstituted human epidermis suggest potential roles in cutaneous innate defense and pathogenic adaptive immunity in psoriasis. J. Immunol. 178:2229-2240.

41. Wolk, K., et al. 2004. IL-22 increases the innate immunity of tissues. Immunity. 21:241-254.

42. Wolk, K., et al. 2006. IL-22 regulates the expression of genes responsible for antimicrobial defense, cellular differentiation, and mobility in keratinocytes: a potential role in psoriasis. Eur. J. Immunol. 36:1309-1323.

43. Boniface, K., et al. 2007. A role for T cell-derived interleukin 22 in psoriatic skin inflammation. Clin. Exp. Immunol. 150:407-415.

44. Murphy, P.M., et al. 2000. International union of pharmacology. XXII. Nomenclature for chemokine receptors. Pharmacol. Rev. 52:145-176.

45. Gerard, C., and Rollins, B.J. 2001. Chemokines and disease. Nat. Immunol. 2:108-115.

46. Schon, M.P., and Ludwig, R.J. 2005. Lymphocyte trafficking to inflamed skin - molecular mechanisms and implications for therapeutic target molecules. Expert Opin. Ther. Targets. 9:225-243.

47. Sallusto, F., Mackay, C.R., and Lanzavecchia, A. 2000. The role of chemokine receptors in primary, effector, and memory immune responses. Annu. Rev. Immunol. 18:593-620.

48. Sallusto, F., Geginat, J., and Lanzavecchia, A. 2004. Central memory and effector memory $\mathrm{T}$ cell sub- 
sets: function, generation, and maintenance. Annu. Rev. Immunol. 22:745-763.

49. Annunziato, F., et al. 2007. Phenotypic and functional features of human Th17 cells. J. Exp. Med. 204:1849-1861.

50. Acosta-Rodriguez, E.V., et al. 2007. Surface phenotype and antigenic specificity of human interleukin 17-producing T helper memory cells. Nat. Immunol. 8:639-646.

51. Singh, S.P., Zhang, H.H., Foley, J.F., Hedrick, M.N., and Farber, J.M. 2008. Human T cells that are able to produce IL-17 express the chemokine receptor CCR6. J. Immunol. 180:214-221.

52. Hirota, K., et al. 2007. Preferential recruitment of CCR6-expressing Th17 cells to inflamed joints via CCL20 in rheumatoid arthritis and its animal model. J. Exp. Med. 204:2803-2812.

53. Homey, B., et al. 2000. Up-regulation of macrophage inflammatory protein-3 alpha/CCL20 and CC chemokine receptor 6 in psoriasis. J. Immunol. 164:6621-6632.

54. Liao, F., et al. 1999. CC-chemokine receptor 6 is expressed on diverse memory subsets of $\mathrm{T}$ cells and determines responsiveness to macrophage inflammatory protein 3 alpha. J. Immunol. 162:186-194.

55. Clark, R.A., et al. 2006. The vast majority of CLA+ $\mathrm{T}$ cells are resident in normal skin. J. Immunol. 176:4431-4439.

56. Teraki, Y., Miyake, A., Takebayashi, R., and Shiohara, T. 2004. Homing receptor and chemokine receptor on intraepidermal $\mathrm{T}$ cells in psoriasis vulgaris. Clin. Exp. Dermatol. 29:658-663.

57. Farber, J.M. 2000. CCR6. In Cytokine reference. J.J. Oppenheim and M. Feldman, editors. Academic Press. London, United Kingdom/San Diego, California, USA. 2081-2086.

58. Varona, R., et al. 2001. CCR6-deficient mice have impaired leukocyte homeostasis and altered contact hypersensitivity and delayed-type hypersensitivity responses. J. Clin. Invest. 107:R37-R45.

59. McDonald, K.G., et al. 2007. CC chemokine receptor 6 expression by B lymphocytes is essential for the development of isolated lymphoid follicles. Am. J. Pathol. 170:1229-1240.

60. Varona, R., Cadenas, V., Flores, J., Martinez, A.C., and Marquez, G. 2003. CCR6 has a non-redundant role in the development of inflammatory bowel disease. Eur. J. Immunol. 33:2937-2946.

61. Cook, D.N., et al. 2000. CCR6 mediates dendritic cell localization, lymphocyte homeostasis, and immune responses in mucosal tissue. Immunity. 12:495-503.

62. Salazar-Gonzalez, R.M., et al. 2006. CCR6-mediated dendritic cell activation of pathogen-specific $\mathrm{T}$ cells in Peyer's patches. Immunity. 24:623-632.

63. Paradis, T.J., Cole, S.H., Nelson, R.T., and Gladue, R.P. 2008. Essential role of CCR 6 in directing activated $\mathrm{T}$ cells to the skin during contact hypersensitivity. J. Invest. Dermatol. 128:628-633.

64. Varona, R., Cadenas, V., Gomez, L., Martinez, A.C., and Marquez, G. 2005. CCR6 regulates CD4+ T-cell-mediated acute graft-versus-host disease responses. Blood. 106:18-26.

65 . Lochner, M., et al. 2008. In vivo equilibrium of proinflammatory IL-17+ and regulatory IL-10+ Foxp3+ RORgamma t+ T cells. J. Exp. Med. 205:1381-1393.

66. Duerr, R.H., et al. 2006. A genome-wide association study identifies IL23R as an inflammatory bowel disease gene. Science. 314:1461-1463.

67. Liang, S.C., et al. 2006. Interleukin (IL)-22 and IL-17 are coexpressed by Th17 cells and cooperatively enhance expression of antimicrobial peptides. J. Exp. Med. 203:2271-2279.

68. Schulz, S.M., et al. 2008. Protective immunity to systemic infection with attenuated Salmonella enterica serovar enteritidis in the absence of IL-12 is associated with IL-23-dependent IL-22, but not IL-17. J. Immunol. 181:7891-7901.

69. Zheng, Y., et al. 2008. Interleukin-22 mediates early host defense against attaching and effacing bacterial pathogens. Nat. Med. 14:282-289.

70. Kopp, T., et al. 2001. Inflammatory skin disease in K14/p40 transgenic mice: evidence for interleukin-12-like activities of $\mathrm{p} 40$. J. Invest. Dermatol. 117:618-626.

71. Schmuth, M., et al. 2002. Expression of the C-C chemokine MIP-3 alpha/CCL20 in human epidermis with impaired permeability barrier function. Exp. Dermatol. 11:135-142.

72. Ivanov, I.I., Zhou, L., and Littman, D.R. 2007. Transcriptional regulation of Th17 cell differentiation. Semin. Immunol. 19:409-417.

73. Gaffen, S.L. 2008. An overview of IL-17 function and signaling. Cytokine. 43:402-407.

74. Nograles, K.E., et al. 2008. Th17 cytokines interleukin (IL)-17 and IL-22 modulate distinct inflammatory and keratinocyte-response pathways. Br. J. Dermatol. 159:1092-1102.
75. Kleinewietfeld, M., et al. 2005. CCR6 expression defines regulatory effector/memory-like cells within the CD25(+)CD4+ T-cell subset. Blood. 105:2877-2886.

76. Lowes, M.A., et al. 2005. Increase in TNF-alpha and inducible nitric oxide synthase-expressing dendritic cells in psoriasis and reduction with efalizumab (anti-CD11a). Proc. Natl. Acad. Sci. U. S. A. 102:19057-19062.

77. Merad, M., et al. 2004. Depletion of host Langerhans cells before transplantation of donor alloreactive $\mathrm{T}$ cells prevents skin graft-versus-host disease. Nat. Med. 10:510-517.

78. Le Borgne, M., et al. 2006. Dendritic cells rapidly recruited into epithelial tissues via CCR6/CCL20 are responsible for CD8 $+\mathrm{T}$ cell crosspriming in vivo. Immunity. 24:191-201.

79. Cella, M., et al. 2009. A human natural killer cell subset provides an innate source of IL-22 for mucosal immunity. Nature. 457:722-725.

80. Luci, C., et al. 2009. Influence of the transcription factor RORgammat on the development of NKp46+ cell populations in gut and skin. Nat. Immunol. 10:75-82.

81. Sanos, S.L., et al. 2009. RORgammat and commensal microflora are required for the differentiation of mucosal interleukin 22-producing NKp46+ cells. Nat. Immunol. 10:83-91.

82. Satoh-Takayama, N., et al. 2008. Microbial flora drives interleukin 22 production in intestinal NKp46+ cells that provide innate mucosal immune defense. Immunity. 29:958-970.

83. MacArthur, R.D., and Novak, R.M. 2008. Reviews of anti-infective agents: maraviroc: the first of a new class of antiretroviral agents. Clin. Infect. Dis. 47:236-241.

84. Tybulewicz, V.L., Crawford, C.E., Jackson, P.K., Bronson, R.T., and Mulligan, R.C. 1991. Neonatal lethality and lymphopenia in mice with a homozygous disruption of the c-abl proto-oncogene. Cell. 65:1153-1163.

85. Lee, S.J., and Nathans, D. 1988. Proliferin secreted by cultured cells binds to mannose 6-phosphate receptors. J. Biol. Chem. 263:3521-3527.

86. Belkaid, Y., et al. 2001. The role of interleukin(IL)-10 in the persistence of Leishmania major in the skin after healing and the therapeutic potential of antiIL-10 receptor antibody for sterile cure. J. Exp. Med. 194:1497-1506 